\title{
ANALYSIS OF THE SPATIOTEMPORAL VARIATION CHARACTERISTICS OF MAIN EXTREME CLIMATE INDICES IN SICHUAN PROVINCE OF CHINA FROM 1968 TO 2017
}

\author{
LI, X. H. - CHEN, Z. F. - WANG, L. \\ Plateau Atmosphere and Environment Key Laboratory of Sichuan Province, School of \\ Atmospheric Sciences, Chengdu University of Information Technology, Chengdu 610225, China \\ *Corresponding author \\ e-mail: 26107184@qq.com; phone: +86-134-0806-9773 \\ (Received $27^{\text {th }}$ Sep 2019; accepted $4^{\text {th }}$ Feb 2020)
}

\begin{abstract}
With an increasing trend in global warming, extreme weather and a variety of related climate events frequently occur in the Southwestern China. In this research, we analyzed daily maximum and minimum temperatures, and daily precipitation data of 39 meteorological stations in the Sichuan Province between the years of 1968 and 2017. Nineteen different indices representing extreme climate change were selected, and linear regression analysis, Mann-Kendall mutation test, sliding T test, wavelet analysis and $\mathrm{R} / \mathrm{S}$ analysis were applied. According to the results, we concluded that: (1) most extreme cold indices showed a decreasing trend, while the extreme warm indices displayed an increasing trend. There was no significant interannual variation for extreme precipitation indices. (2) Most extreme temperature indices presented no significant mutation years, and the significant periods were mainly 2-6 years long. The mutation years of heavy and very heavy precipitation events mainly appeared in the 1980 and the early $21^{\text {st }}$ century, and the significant periods of most extreme precipitation indices were 2-7 years long. (3) As shown by the Hurst exponent analysis and interannual variation trends, it is very likely that the extreme temperature and extreme precipitation events in the Sichuan Province will increase in the future.
\end{abstract}

Keywords: extreme temperature indices, extreme precipitation indices, $M-K$ test, sliding $T$ test, wavelet analysis, $R / S$ analysis

\section{Introduction}

According to the IPCC (Intergovernmental Panel on Climate Change, IPCC) Fifth Assessment Report, from 1880 to 2012 the global mainland and sea surface temperature increased by $0.85^{\circ} \mathrm{C}$. The change in temperature for the $2003-2012$ period was $0.78^{\circ} \mathrm{C}$ higher than for the period 1850 to 1990 (Stocker, et al., 2013). In the second half of the $20^{\text {th }}$ century, the number of cold nights on land in over $70 \%$ of the areas worldwide began to show a significant decrease, while the number of warm nights increased (Alexander, et al., 2006). Extreme temperatures mainly manifest as more frequent incidences of extreme high and low temperature events and a prolongation of their duration. Extreme precipitation events mainly manifest with an increasing frequency and intensity of droughts, rainstorms, and extraordinary flood disasters (Ding, et al., 2018). As indicated by historical observations, in the past century global warming led to an increase in the intensity and frequency of extreme events (droughts, floods, and cold waves), as well as an expansion of the area of influence (Zhao, et al., 2016; Liu, et al., 2019).

At present, under the general context of global warming, extreme climate changes at different scales have attracted the attention of researchers all over the world. Alexander et al. (2006) have stated that, on a global scale, global warming has caused a significant reduction in the number of cold nights and a significant increase in the number of warm nights in many regions worldwide. The extreme precipitation indices including the number of continuous rainless days and number of continuous rainy days have also 
substantially increased (Easterling, et al., 2000). Song et al. (2013) analyzed the extreme temperature events all over the world from 1981 to 2010. They determined that the frequency of occurrence of heat and cold waves increased 2.7 and 6.4 times, respectively. On a regional scale, scholars have determined that the number of cold days and nights has been continuously decreasing, while the number of warm days and nights has been increasing. Similar variation trends have been observed for extreme temperature and precipitation events on a global scale. For example, in the United States, the increasing trends were identified for temperature, and the frost and ice days dwindled as growing season length, tropical nights and summer days increased (Sohrabi, et al., 2013). In Europe, significant increasing trends in annual precipitation extremes have been detected in different regions (Vogel, et al., 2018; Arnone, et al., 2018). The extreme temperature indices of Nile river basin decreased in cold, but increased in warm night/days, and most precipitation extreme indices increased (Tariku and Gan, 2018). For the Caribbean small islands, most extreme temperature indices at Piarco Point (Trinidad) showed significant warming trends on annual and seasonal scales as well as for most months. For Crown Point (Tobago), trends indicated an increase in annual precipitation totals and extremely wet days were observed (Dookie, et al., 2018). In some Asian country, with a large proportion of stations having statistically significant trends for all temperature indices, temperature extremes showed a warming trend over Iran (Soltani, et al., 2016). Sajjad and Ghaffar (2018) observed and projected extreme climate indices over Pakistan in changing climate, the results showed there were a significantly increasing trend in the mean maximum temperature and summer days, and frequency of heavy precipitation also significantly increased. In addition, studies on extreme temperatures and precipitation occurrences have shown that in most Chinese regions, the cold night index and warm night index displayed a similar intensity and yet an opposite trend of variation, which indicated a good symmetry (Yang, et al., 2010). Both, the frequency and intensity of extreme precipitation events have been increasing, though with apparent inter-regional differences (Jiang, et al., 2017; Yin and Sun, 2019). Some researchers have suggested that the extreme precipitation events have been increasing in the Yangtze River Basin and part of Southeastern China and Northwestern China. However, a decreasing trend was observed for some parts of Northern, Northeastern, and Southwestern China (Gao and Xie, 2014).

Two abnormal drought events occurring in 2005-2006 and 2009-2010 in Southwestern China have drawn widespread attention regarding extreme climate incidents in this region. Yuan and Zheng (2015) studied extreme temperature indices observed in Southwestern China during the period 1962 to 2012. In general, extreme high and low temperature events showed an increasing and decreasing tendency, respectively. An opposite variation trend was observed in some regions, which was a unique climate change feature of Southwestern China. In addition, when considering extreme precipitation events for the same period and region, results indicated that there was a large variability. The extreme precipitation events showed an overall increasing trend during the past 50 years; however, it was not significant. This may be related to abnormal changes in sea surface temperature and complex geographical environments (Yuan, et al., 2014). Luo et al. (2016) determined the trend for extreme temperatures in Southwestern China for the years of 1970 to 2010. Their results showed that there was a good local symmetry between the number of warm days and the number of cold days in this region, as well as a good symmetry between the number of warm nights and number of cold nights for the past 41 years. The warm indices increased in value, while 
the cold indices decreased. Ding (2014) studied the spatio-temporal changes of extreme precipitation in Southwestern China, and the results indicated that the frequency of extreme precipitations in this area have increased since the 1960s. There were significant inter-regional differences in inter-decadal variations. The frequency of extreme precipitations in the monsoon period significantly increased, while that in the non-monsoon period decreased.

The Sichuan Province is located in Southwestern China and marks the transition belt between the Tibetan Plateau of China and the eastern plain. With a complex landform and diverse climate types, it is a sensitive, vulnerable and strategic area affected by climate change. The inter-regional difference in temperature in this province can reach more than $20^{\circ} \mathrm{C}$, and the regional precipitation distribution varies significantly. In recent years, the occurrence of extreme climate events has led to frequent natural disasters in the Sichuan Province. For example, in 2006, this area suffered an extraordinary drought that was estimated to occur only once-in-a-hundred-year period. From the winter of 2009 to the spring of 2010, a persistent severe drought affected 71 cities, districts and counties of 13 Sichuanese municipalities. It was estimated that this drought affected a population of 8.282 million, a crop area of $511000 \mathrm{hm}^{2}$, with a resulting direct economic loss of 1.38 billion RMB. In this same area, in 2011, the numbers were as follows: crop area affected by the drought reached the $346000 \mathrm{hm}^{2}$, and the direct economic loss was of 1.2 billion RMB (Wang, et al., 2017). In 2012 and 2017, another historical extreme temperature hit the summer season in this same province. In July of 2007, the Sichuan Basin was struck by a once-in-a-hundred-year extraordinary heavy rain. On July $19^{\text {th }}$ in the year of 2010 , a heavy severe flood hit Guang'an City in Sichuan. In July of 2016, a persistent rainstorm occurred in Jiuzhaigou, which triggered a severe debris flow disaster and resulted in the shutdown of the Jiuzhaigou Scenic Area. In July of 2018, Mianyan area in Sichuan was hit by the most severe flood ever seen since the founding of New China. These extreme climate events have resulted in enormous economic losses to the Sichuan province, threatening people's life and property safety. A variety of studies related to the extreme temperatures and precipitation events in Sichuan have been conducted. For example, Liu (2013) defined extreme temperature events based on percentile thresholds at three representative stations in the Sichuan Basin (Chengdu, Nanchong, and Shapingba). His study showed that from the mid-1970s to the 1980s, the frequency and intensity of extreme high temperature events in the Sichuan Basin decreased. However, after the late-1990s, the frequency and intensity of extreme high temperature events increased, while the variation trend of extreme low temperature events was just the opposite. Sun et al. (2017) studied the extreme precipitation events of Sichuan that occurred between 1971 and 2014. They found out that in the past 44 years, the overall precipitation in this region slightly decreased. In addition, there was a general warming and drying trend in most parts of Sichuan, except for an increasing humidity pattern observed in the Western Sichuan Plateau. However, the investigations dealing with the distinctive topography and climate conditions in this area are far from being enough.

In view of the above, the objective of this study was to investigate the spatiotemporal and abrupt changes, as well as periodic trends in extreme temperature and precipitation in the Sichuan Province for the period 1968 to 2017 by using 10 extreme temperature indices and 9 extreme precipitation indices, which are recommended by the WMO (World Meteorological Organization, WMO). Furthermore, to explore the relationship between extreme climate indices and geographical factors and to project 
future change trends by using Hurst exponent. Through deep and comprehensive analysis, our research findings provide valuable information that may help in coping with climate change and for disaster prevention and relief in the Sichuan Province.

\section{Materials and methods}

\section{Study area}

The Sichuan Province is located in Southwestern China $\left(97^{\circ} 21^{\prime} \sim 108^{\circ} 33^{\prime}\right.$ longitude and $26^{\circ} 03^{\prime} \sim 34^{\circ} 19^{\prime}$ latitude). The entire region covers an area of $485000 \mathrm{~km}^{2}$, it is 1 $075 \mathrm{~km}$ from east to west and $921 \mathrm{~km}$ from south to north (Zhan and Wen, 2006). The terrain is higher to the west and lower to the east. To the northwest, the area is mainly covered by plateaus and high mountains, while the southwest is a mountainous region, and the eastside is both, basin and mountains. Due to the varied landforms and the alternating influence of different monsoon winds, a unique climatic type has been formed. Taking into account temperature, precipitation, and sunshine conditions, the Sichuan Province can be divided into three major climatic zones: (1) A cold climatic zone in the high mountains and plateaus in the Northwestern area. Herein, there is an annual average temperature between $4 \sim 12{ }^{\circ} \mathrm{C}$; the winter is cold and the summer is cool, and the total annual precipitation is only 500-900 $\mathrm{mm}$. Also, the annual sunshine hours are as many as $1600 \sim 2600$; (2) The subtropical semi-humid climatic zone in the mountainous areas in Southwestern Sichuan, where the annual average temperature oscillates between $12 \sim 20^{\circ} \mathrm{C}$, and the total annual precipitation is $900 \sim 1200 \mathrm{~mm}$; however, $90 \%$ of the precipitation occurs from May to October, and the annual sunshine hours are between 2 000 2 600; (3) The middle subtropical humid climatic zone in the Sichuan Basin with an intermediate annual average temperature of $16 \sim 18{ }^{\circ} \mathrm{C}$; the winter is warm and the summer is hot; the annual precipitation is abundant (1000 1 $200 \mathrm{~mm}$ ) and the annual sunshine hours are short (only 1 000-1 400) (Zhou, et al., 2011). The inter-regional climatic differences are significant in the Sichuan Province. Large climatic variations are related to altitude. Rapid climatic changes have led to a great number of meteorological disasters, such as droughts, rainstorms, floods and low temperature freezing events. These disasters have frequently occurred and they have affected extensive regions (Ma, 2016). Figure 1 shows the geographical location of the Sichuan Province and a zoning map of this area based on terrain and climate.

\section{Data sources}

The main data source used in this study was collected from the MDSCC (Meteorological Data Service Center of China, MDSCC) (http://www.nmic.cn), and the principles of continuity and longest duration were considered. The data on daily maximum temperature, daily minimum temperature, $24 \mathrm{~h}$ precipitation and annual precipitation at 39 meteorological stations from 1968 to 2017 were collected. Three quality control methods were used in handling these data, namely, internal consistency check, climate limit value check and station extreme check. Linear regression was applied in order to calculate missing data by interpolation using the available information on adjacent stations. In this endeavor, care was taken in order to ensure that the corrected meteorological data displayed high scientificity, accuracy, and continuity. Figure 2 and Table 1 show the spatial distribution, detailed information, and zone division for each station. 


\section{Extreme climate indices}

In this study, from all extreme climate indices recommended by the WMO, we selected 10 extreme temperature indices and 9 extreme precipitation indices (Table 2). These data were extracted by running the program.

Table 1. Detailed information of meteorological stations in Sichuan Province used in the study

\begin{tabular}{|c|c|c|c|c|c|}
\hline Zoning & No. & Station names & Latitude $\left({ }^{\circ} \mathbf{N}\right)$ & Longitude $\left({ }^{\circ} \mathbf{E}\right)$ & Elevation $(\mathbf{m})$ \\
\hline \multirow{17}{*}{$\begin{array}{c}\text { Eastern Sichuan } \\
\text { Basin (ESB) }\end{array}$} & 1 & WenJiang & 103.94 & 30.82 & 548.9 \\
\hline & 2 & DuJiangYan & 103.79 & 31.07 & 699.7 \\
\hline & 3 & MianYang & 104.62 & 31.39 & 523.7 \\
\hline & 4 & Ya'an & 103.10 & 29.98 & 629.4 \\
\hline & 5 & EMeiShan & 103.33 & 29.51 & 3048.3 \\
\hline & 6 & LeShan & 130.76 & 29.57 & 425.2 \\
\hline & 7 & YiBin & 104.60 & 28.80 & 342.1 \\
\hline & 8 & GuangYuan & 105.85 & 32.44 & 513.5 \\
\hline & 9 & WanYuan & 108.05 & 32.07 & 675.0 \\
\hline & 10 & LangZhong & 106.02 & 31.46 & 385.4 \\
\hline & 11 & BaZhong & 106.86 & 31.87 & 416.3 \\
\hline & 12 & DaXian & 107.50 & 31.19 & 344.4 \\
\hline & 13 & SuiNing & 105.54 & 30.50 & 355.3 \\
\hline & 14 & GaoPing & 106.09 & 30.76 & 311.0 \\
\hline & 15 & XuYong & 105.46 & 28.19 & 378.6 \\
\hline & 16 & $\mathrm{NanBu}$ & 106.07 & 31.35 & 406.9 \\
\hline & 17 & $\mathrm{NaXi}$ & 105.40 & 28.79 & 369.4 \\
\hline \multirow{7}{*}{$\begin{array}{c}\text { Mountainous } \\
\text { area in } \\
\text { southwestern } \\
\text { Sichuan (MSW) }\end{array}$} & 18 & $\mathrm{MuLi}$ & 101.27 & 27.93 & 2424.6 \\
\hline & 19 & YueXi & 102.52 & 28.65 & 1660.1 \\
\hline & 20 & ZhaoJue & 102.86 & 28.02 & 2133.7 \\
\hline & 21 & LeiBo & 103.58 & 28.27 & 1254.8 \\
\hline & 22 & YanYuan & 101.51 & 27.44 & 2545.0 \\
\hline & 23 & XiChang & 102.26 & 27.90 & 1592.7 \\
\hline & 24 & HuiLi & 102.25 & 26.66 & 1788.6 \\
\hline \multirow{15}{*}{$\begin{array}{c}\text { Alpine and } \\
\text { plateau area in } \\
\text { northwestern } \\
\text { Sichuan (PNW) }\end{array}$} & 25 & ShiQu & 98.09 & 32.99 & 4201.0 \\
\hline & 26 & RuoErGao & 103.02 & 33.64 & 3442.6 \\
\hline & 27 & $\mathrm{DeGe}$ & 98.58 & 31.82 & 3185.0 \\
\hline & 28 & GanZi & 100.00 & 31.63 & 3394.6 \\
\hline & 29 & $\mathrm{SeDa}$ & 100.30 & 32.28 & 3895.8 \\
\hline & 30 & $\mathrm{DaoFu}$ & 101.14 & 31.01 & 2959.2 \\
\hline & 31 & MaErKang & 102.22 & 31.87 & 2666.3 \\
\hline & 32 & HongYuan & 102.59 & 32.79 & 3492.8 \\
\hline & 33 & XiaoJin & 102.34 & 31.00 & 2368.8 \\
\hline & 34 & SongPan & 103.56 & 32.65 & 2852.1 \\
\hline & 35 & BaTang & 99.07 & 30.01 & 2590.2 \\
\hline & 36 & XinLong & 100.35 & 30.92 & 2999.2 \\
\hline & 37 & DaoCheng & 100.30 & 29.14 & 3728.6 \\
\hline & 38 & KangDing & 101.99 & 30.04 & 2615.5 \\
\hline & 39 & JiuLong & 101.50 & 29.01 & 2931.4 \\
\hline
\end{tabular}


Table 2. List of the 19 selected extreme climate indices

\begin{tabular}{|c|c|c|c|c|}
\hline Categories & No. & Indices & Descriptive names/units & Definitions \\
\hline \multirow{10}{*}{$\begin{array}{l}\text { Extreme } \\
\text { temperature } \\
\text { indices }\end{array}$} & 1 & FD & Frost days/d & $\begin{array}{l}\text { Annual count when } \mathrm{Tn} \text { (daily } \\
\text { minimum) }<0^{\circ} \mathrm{C}\end{array}$ \\
\hline & 2 & Tnn & $\operatorname{Min} \mathrm{Tmin} /{ }^{\circ} \mathrm{C}$ & $\begin{array}{l}\text { Annual minimum value of daily minimum } \\
\text { temperature }\end{array}$ \\
\hline & 3 & Tnx & $\operatorname{Max} \operatorname{Tmin} /{ }^{\circ} \mathrm{C}$ & $\begin{array}{l}\text { Annual maximum value of daily minimum } \\
\text { temperature }\end{array}$ \\
\hline & 4 & Tn10 & Cool nights/d & Number of days when $\mathrm{Tn}<10$ th percentile \\
\hline & 5 & Tx10 & Cool days/d & $\begin{array}{c}\text { Number of days when Tx (daily } \\
\text { maximum) }<10 \text { th percentile }\end{array}$ \\
\hline & 6 & SU & Summer days/d & Annual count when $\mathrm{Tx}>25^{\circ} \mathrm{C}$ \\
\hline & 7 & Txn & $\operatorname{Min} \operatorname{Tmax} /{ }^{\circ} \mathrm{C}$ & $\begin{array}{l}\text { Annual minimum value of daily maximum } \\
\text { temperature }\end{array}$ \\
\hline & 8 & Txx & $\operatorname{Max} \operatorname{Tmax} /{ }^{\circ} \mathrm{C}$ & $\begin{array}{l}\text { Annual maximum value of daily maximum } \\
\text { temperature }\end{array}$ \\
\hline & 9 & Tn90 & Warm nights/d & Number of days when $\mathrm{Tn}>$ 90th percentile \\
\hline & 10 & Tx90 & Warm days/d & Number of days when $T x>90$ th percentile \\
\hline \multirow{9}{*}{$\begin{array}{l}\text { Extreme } \\
\text { precipitation } \\
\text { indices }\end{array}$} & 11 & CDD & Consecutive dry days/d & $\begin{array}{l}\text { Maximum number of consecutive days with } \\
\qquad R R>1 \mathrm{~mm}\end{array}$ \\
\hline & 12 & CWD & Consecutive wet days/d & $\begin{array}{l}\text { Maximum number of consecutive days with } \\
\qquad \mathrm{RR} \geq 1 \mathrm{~mm}\end{array}$ \\
\hline & 13 & R10 & $\begin{array}{l}\text { Number of heavy } \\
\text { precipitation days/d }\end{array}$ & Annual count of days when $P R C P \geq 10 \mathrm{~mm}$ \\
\hline & 14 & R20 & \begin{tabular}{|c|}
$\begin{array}{c}\text { Number of very heavy } \\
\text { precipitation days/d }\end{array}$ \\
\end{tabular} & Annual count of days when $P R C P \geq 20 \mathrm{~mm}$ \\
\hline & 15 & R50 & Number of rainstorm days/d & Annual count of days when $P R C P \geq 50 \mathrm{~mm}$ \\
\hline & 16 & R95p & Very wet days/mm & $\begin{array}{l}\text { Annual total PRCP when RR > 95th } \\
\text { percentile }\end{array}$ \\
\hline & 17 & R99p & Extremely wet days/mm & $\begin{array}{l}\text { Annual total PRCP when RR > 99th } \\
\text { percentile }\end{array}$ \\
\hline & 18 & SDII & $\begin{array}{l}\text { Simple daily intensity } \\
\text { index } /(\mathrm{mm} / \mathrm{d})\end{array}$ & $\begin{array}{l}\text { Annual total precipitation divided by the } \\
\text { number of wet days }\end{array}$ \\
\hline & 19 & PRCPTOT & $\begin{array}{l}\text { Annual total wet-day } \\
\text { precipitation/mm }\end{array}$ & Annual total PRCP in wet days ( $R R \geq 1 \mathrm{~mm})$ \\
\hline
\end{tabular}

RR: daily precipitation; PRCP: precipitation

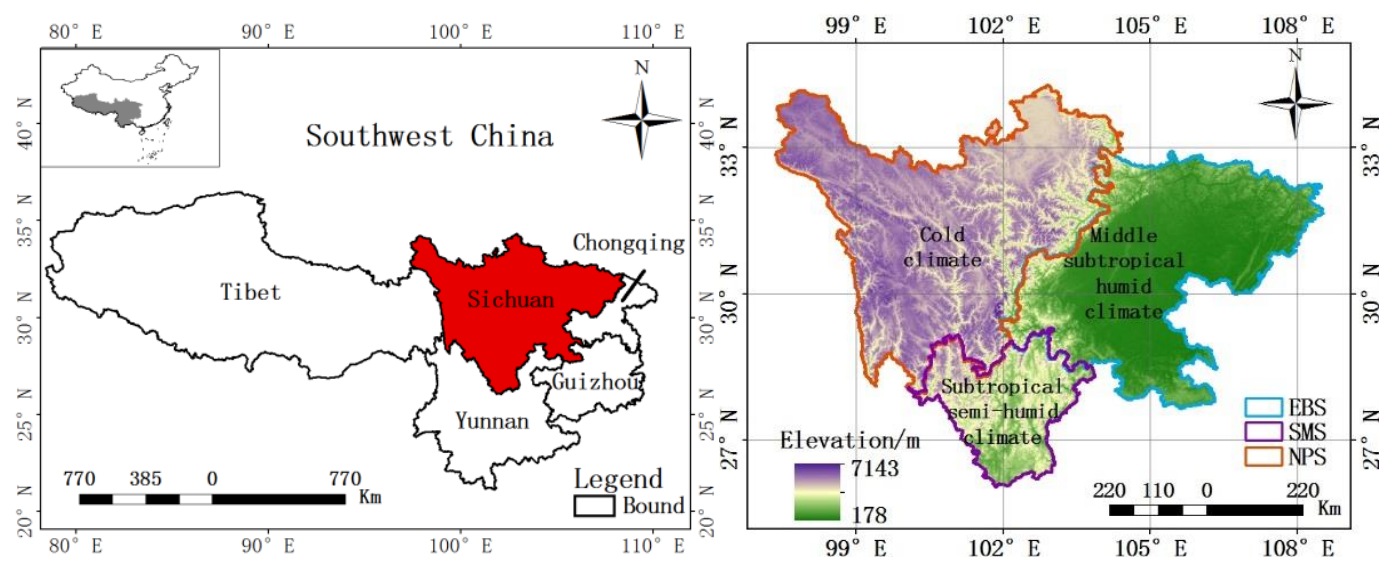

Figure 1. Geographical location and zoning map based on terrain and climate in study area 


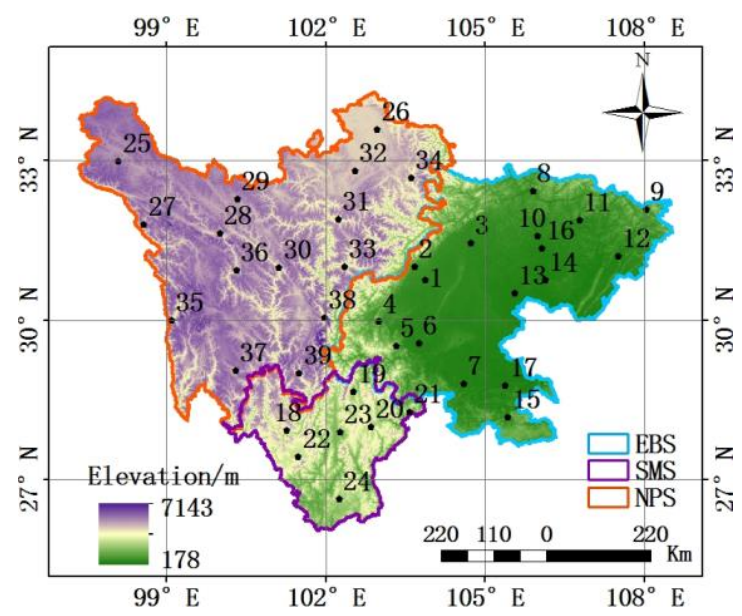

Figure 2. The spatial distribution of 39 meteorological stations in Sichuan Province

\section{Main research methods}

The following analyses or tests were performed: linear regression, Mann-Kendall trend test, sliding $\mathrm{T}$ test, wavelet, correlation, and R/S analyses. The main methods involved in the present study were as follows:

(1) Mann-Kendall trend test: it is also known as the M-K or nonparametric test. This method is recommended by the WMO, and is a valuable tool for effectively differentiating natural fluctuations from definite variation trends. It is a nonparametric statistical test to analyze the variation trends of climate and hydrological series over time. It is also used for the detection of precipitation trends as well as drought frequency under the influence of climate change (Liu, et al., 2011a). Samples used for M-K test may or may not conform to anormal distribution. In addition, analysis is not affected when samples display a few outliers. For these reasons, M-K test surpasses other tools when dealing with abrupt climate changes (Ma, et al., 2018). The main steps of M-K test are listed below (Wei, 2007):

For time series $\mathrm{X}$ comprising $\mathrm{n}$ samples, a rank sequence is constructed as:

$$
S_{k}=\sum \begin{aligned}
& k \\
& i=1
\end{aligned} r_{i}=\left\{\begin{array}{l}
1, x_{i}>x_{j} \\
0, x_{i} \leq x_{j}
\end{array}, \quad j=1,2, \ldots, i\right.
$$

where $\mathrm{k}$ is: the sample size; $\mathrm{r}_{\mathrm{i}}$ is used to determine whether the value at time $\mathrm{i}$ is larger than that at time $\mathrm{j}$; the rank sequence $S_{k}$ represents the cumulative number when values are larger at time $\mathrm{j}$ than those at time $i$.

Statistics is defined as:

$$
U F_{k}=\frac{S_{k}-E\left(S_{k}\right)}{\sqrt{\operatorname{Var}\left(S_{k}\right)}}, k=1,2, \ldots, n
$$

where:

$$
E\left(S_{k}\right)=\frac{n(n+1)}{4}
$$




$$
\operatorname{Var}\left(S_{k}\right)=\frac{n(n-1)(2 n+5)}{72}
$$

where $\mathrm{UF}_{1}=0, E\left(S_{k}\right), \operatorname{Var}\left(S_{k}\right)$ is the mean and variance of the rank sequence $S_{k} . \mathrm{UF}_{\mathrm{i}}$ obeys a normal distribution. Through Equation 2, a positive UF trend was obtained. The same method was applied to the inverted series to obtain the corresponding UB curve, i.e., $U_{k}=-U F_{k}$. When plotting the curves, if the UF test statistics result is above 0 , the variable has an increasing trend. On the contrary, if the UF test statistics result is below 0 , the variable has a decreasing trend. In addition, an intersection point between the UF and UB statistics result lying between the critical lines determines the starting time of climate alteration, i.e, the year of climate change.

(2) Sliding T test: This test is helpful in detecting climate mutations by determining if there is a significant difference in the means of two different groups. The basic principle is that the significant difference between the means of two subseries in one given climate series is tested by treating such difference as if it is the result of comparing two separate series. Should the difference in the means of the two subseries exceed a certain significance level, the means are considered to have undergone qualitative change, i.e., the mutation occurred.

For a time series $\left\{X_{i}, i=1,2, \ldots, n\right\}$ composed of $n$ samples, a given time is selected as the reference point. Before and after this point, $\mathrm{n}_{1}$ and $\mathrm{n}_{2}$ represent the number of elements in the samples for their corresponding two sub-sequences $\mathrm{X}_{1}$ and $\mathrm{X}_{2}$ (generally $\mathrm{n}_{1}=\mathrm{n}_{2}$ ). The means of the two sub-sequences are $\overline{\mathrm{X}_{1}}$ and $\overline{\mathrm{X}_{2}}$, and the variances $\mathrm{s}_{1}^{2}$ and $\mathrm{s}_{2}^{2}$, respectively. Statistics is defined as (Liu, et al., 2011b):

$$
t=\frac{\bar{x}_{1}-\bar{x}_{2}}{S \sqrt{\frac{1}{n_{1}}+\frac{1}{n_{2}}}}
$$

where:

$$
S=\sqrt{\frac{n_{1} s_{1}^{2}+n_{2} s_{2}^{2}}{n_{1}+n_{2}-2}}
$$

Then, $\mathrm{t}$ obeys a $\mathrm{t}$ distribution with a degree of freedom $\mathrm{n}_{1}+\mathrm{n}_{2}-2$.

(3) Wavelet analysis: This is a method for the analysis of signal frequency and has a multi-resolution capacity. Wavelet analysis accurately provides information on local signal features in both, the time and frequency domains, and can be used for multiscale detailed signal analysis. Since this method is more robust than Fourier transform, it has been widely used in multi-scale climate analysis in recent years $(\mathrm{Xu}$, et al., 2004).

The wavelet function is defined as follows: Let the function $\varphi(t)$ be a squareintegrable function, i.e., $\varphi(t) \in \mathrm{L}^{2}(\mathrm{R})$, where $\mathrm{R}$ is any real number. If the Fourier transform $\psi(\omega)$ satisfies the admissibility condition (Wei, 2007): 


$$
\int_{R} \frac{|\psi(\omega)|^{2}}{\omega} d \omega<\infty
$$

then $\varphi(t)$ is called a basic wavelet or wavelet generating function. By expansion and translation of the wavelet function $\varphi(t)$, the continuous wavelet is obtained as:

$$
\varphi_{a, t}(t)=\frac{1}{\sqrt{a}} \varphi\left(\frac{t-\tau}{a}\right), a, \tau \in R, a>0
$$

For any function $f(t) \in L^{2}(R)$, the continuous wavelet changes into

$$
W_{f}(a, \tau)=\left\langle f(t), \varphi_{a, \tau}(t)\right\rangle=\frac{1}{\sqrt{a}} \int_{R} f(t) \varphi\left(\frac{t-\tau}{a}\right) d t
$$

where $a$ is the scale factor; $\tau$ is the translation factor; and $W_{f}(a, \tau)$ is the wavelet coefficient.

Herein, the Morlet wavelet was used for continuous wavelet transform of the extreme climate indices. The wavelet function is:

$$
\psi(t)=e^{i \omega t} e^{-t^{2} / 2}
$$

(4) R/S analysis: This is also known as rescaled range analysis, which is an important analytical method under the chaos theory. It can be applied to analyze the fractal features and long-term memory process of a variety of time series. The calculation method is illustrated below:

A time series $\left\{X_{t}\right\}$ is divided into A subintervals with equal length $\mathrm{N}$. For each subinterval, let

$$
X_{t, n}=\sum_{u=1}^{t}\left(X_{u}-M_{n}\right)
$$

Where $M_{n}$ is the mean of the $n^{\text {th }}$ internal $X_{u} ; X_{t, n}$ is the cumulative dispersion of the $n^{\text {-th }}$ interval; $\mathrm{u}$ is the time series. Also,

$$
R=\max \left(X_{t, n}\right)-\min \left(X_{t, n}\right)
$$

where $\max \left(X_{t, n}\right)$ and $\min \left(X_{t, n}\right)$ are the maximum and minimum values, respectively. Let $S$ be the standard deviation of the $X_{u}$ series, then the rescaled range R/S can be defined. Through long-term practice, the following relationship can be established in terms of the Hurst exponent:

$$
R / S=K(n)^{H}
$$


where $\mathrm{H}$ is the Hurst exponent and $\mathrm{K}(\mathrm{n})$ is a constant. Logarithm is taken on both sides to calculate the Hurst exponent, which can be used to measure the trend intensity and noise level variation over time. It is a measure of statistical correlation of time series (Zhao, et al., 2000).

Based on the above methods, first, a linear regression analysis was performed for the 19 extreme climate indices, and the spatio-temporal variation trend for each extreme climate index from 1968 to 2017 was obtained. In order to identify the major stages in the variation, a Mann-Kendall trend test and sliding $\mathrm{T}$ test were respectively implemented. By comparing and verifying the results of the two tests already mentioned, the year of abrupt change was determined. Next, a wavelet analysis with high resolution for the waveform characteristics was used to derive the periodic features of the climatic index changes. Given the relevant influence of terrain on climate, a correlation analysis between climate indices and geographical factors was performed. With this, it was possible to measure such degree of influence. Finally, $\mathrm{R} / \mathrm{S}$ analysis was done with the purpose of predicting future climate trends in the Sichuan Province.

\section{Results}

\section{Spatio-temporal variation characteristics of extreme temperature indices}

\section{Interannual temporal variations}

Extreme weather events refer to a kind of rare events occurring at a specific area and time. The occurrence of extreme weather events can be estimated using extreme climate indices. Figure 3 displays the interannual variation trend for extreme temperature indices observed in the Sichuan Province from 1968 to 2017. Specifically, Figure 3a-e shows the five extreme cold indices FD, Tnn, Tnx, Tn10, and Tx10, among the ten extreme temperature indices, where linear tendency rates indicated either a decreasing or a warming trend. The inter-decadal variation tendency rates for those indices were $133.73 \mathrm{~d} / 10 \mathrm{a}, 0.64{ }^{\circ} \mathrm{C} / 10 \mathrm{a}, 0.23{ }^{\circ} \mathrm{C} / 10 \mathrm{a},-296.75 \mathrm{~d} / 10 \mathrm{a}$, and $-132.97 \mathrm{~d} / 10 \mathrm{a}$, respectively. In Figure 3f-j, the five extreme warm indices include SU, Txn, Txx, Tn90, and Tx90, where their linear tendency rates indicated either an increasing or a warming trend. In this case, the inter-decadal variation tendency rates were $32.30 \mathrm{~d} / 10 \mathrm{a}, 0.28{ }^{\circ} \mathrm{C} / 10 \mathrm{a}$, $0.39^{\circ} \mathrm{C} / 10 \mathrm{a}, 272.1 \mathrm{~d} / 10 \mathrm{a}$, and $273.7 \mathrm{~d} / 10 \mathrm{a}$, respectively. For all these results, the tendency rates complied with the 0.05 significance level test. In addition, it was observed that the FD, Tnn, and Tx90 variation amplitudes were significantly higher than those corresponding to SU, Txn and Tx10 values. These results represented an asymmetry in temporal variation features of the extreme cold and warm indices. Generally speaking, warming was predominant in the Sichuan Province, which is a region with positive response to global warming.

Figure 4 shows the spatial distribution for the regression coefficients of extreme temperature indices observed in 39 meteorological stations of the Sichuan province for the past 50 years. Results indicated that among the five extreme cold indices, FD, Tn10, and Tx10 showed a decreasing trend in space, while Tnn and Tnx were the opposite. In general, the 5 extreme warm indices showed a warming or increasing trend, which was consistent with the interannual variation. For all these results, the regression coefficients complied with the 0.05 significance level test. The overall FD reduction was of $-10 \sim 0 \mathrm{~d} / 10 \mathrm{a}$, and the Muli Station displayed the largest reduction data 
with an inter-decadal variation of-19.5d/10a; Yuexi was the only station with a positive increase, showing an inter-decadal variation of $0.3 \mathrm{~d} / 10 \mathrm{a}$. These two stations are both located in the MSW. More significant changes were observed in the mountainous regions, where the highest average variation rate was of $-5.73 \mathrm{~d} / 10 \mathrm{a}$. These types of changes were mostly insignificant in the basin regions, where the lowest average variation rate was obtained as $-1.51 \mathrm{~d} / 10 \mathrm{a}$. The overall $\mathrm{Tnn}$ increasing range was $0 \sim 0.5^{\circ} \mathrm{C} / 10 \mathrm{a}$, and the fastest increase was found at the Muli Station $\left(1.1^{\circ} \mathrm{C} / 10 \mathrm{a}\right)$. Tnn decreased only at the Yuexi Station $\left(-0.21^{\circ} \mathrm{C} / 10 \mathrm{a}\right)$. These two stations are located in the mountainous region. The average variation trend of Tnn was $0.46{ }^{\circ} \mathrm{C} / 10 \mathrm{a}$ in the MSW vs. $0.55^{\circ} \mathrm{C} / 10 \mathrm{a}$ in the PNW (a total of 9 stations had a variation rate larger than $\left.0.5^{\circ} \mathrm{C} / 10 \mathrm{a}\right)$. The ESB displayed the smallest variation $\left(0.27^{\circ} \mathrm{C} / 10 \mathrm{a}\right)$. Regarding Tnx, the Muli Station showed the highest increasing trend $\left(0.64{ }^{\circ} \mathrm{C} / 10 \mathrm{a}\right)$. In addition, only the Shaojue Station contained a negative change, which was $-0.05^{\circ} \mathrm{C} / 10 \mathrm{a}$. Among different terrain types, the largest average increasing trend was obtained in the PNW $\left(0.29^{\circ} \mathrm{C} / 10 \mathrm{a}\right)$.
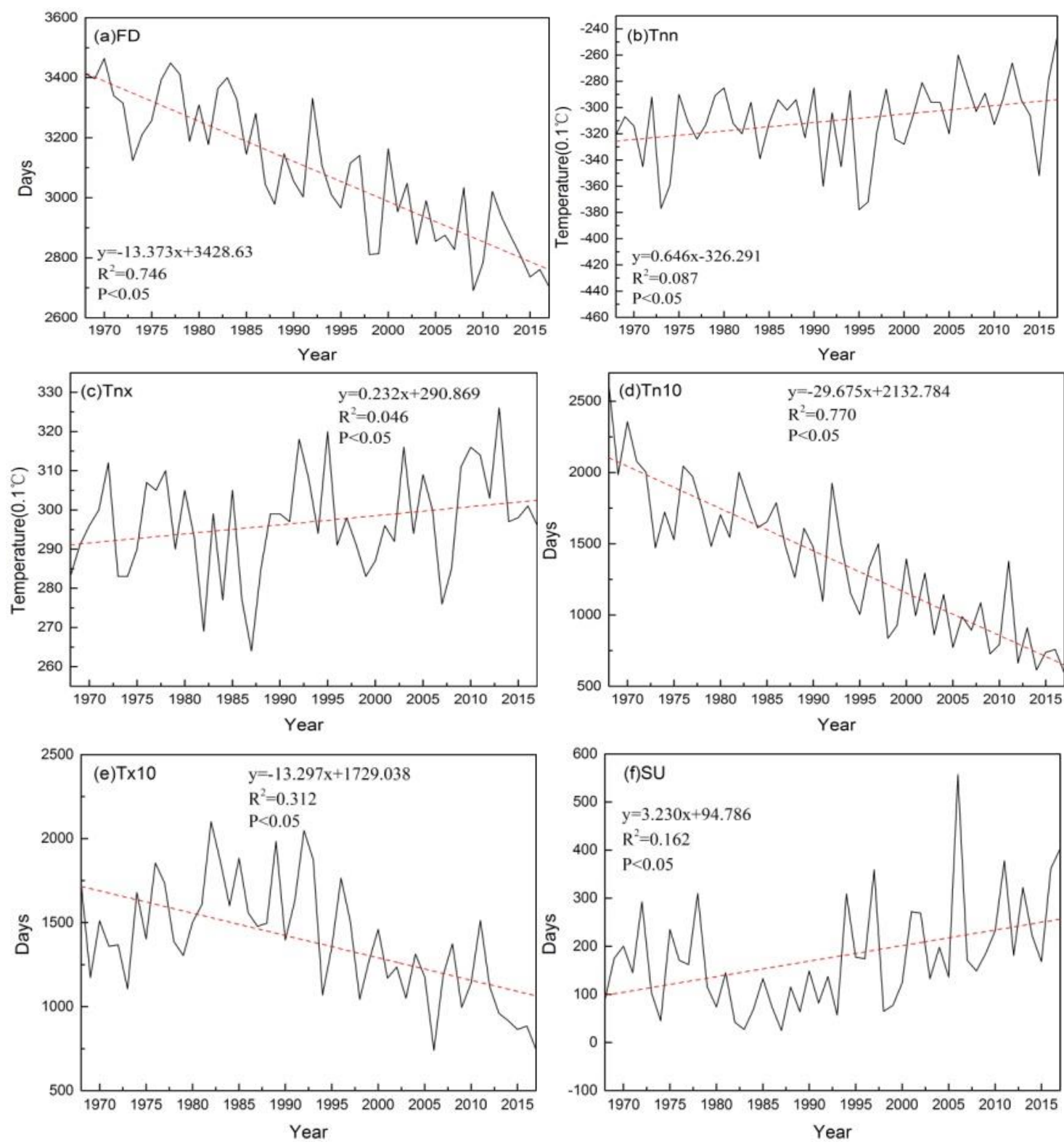

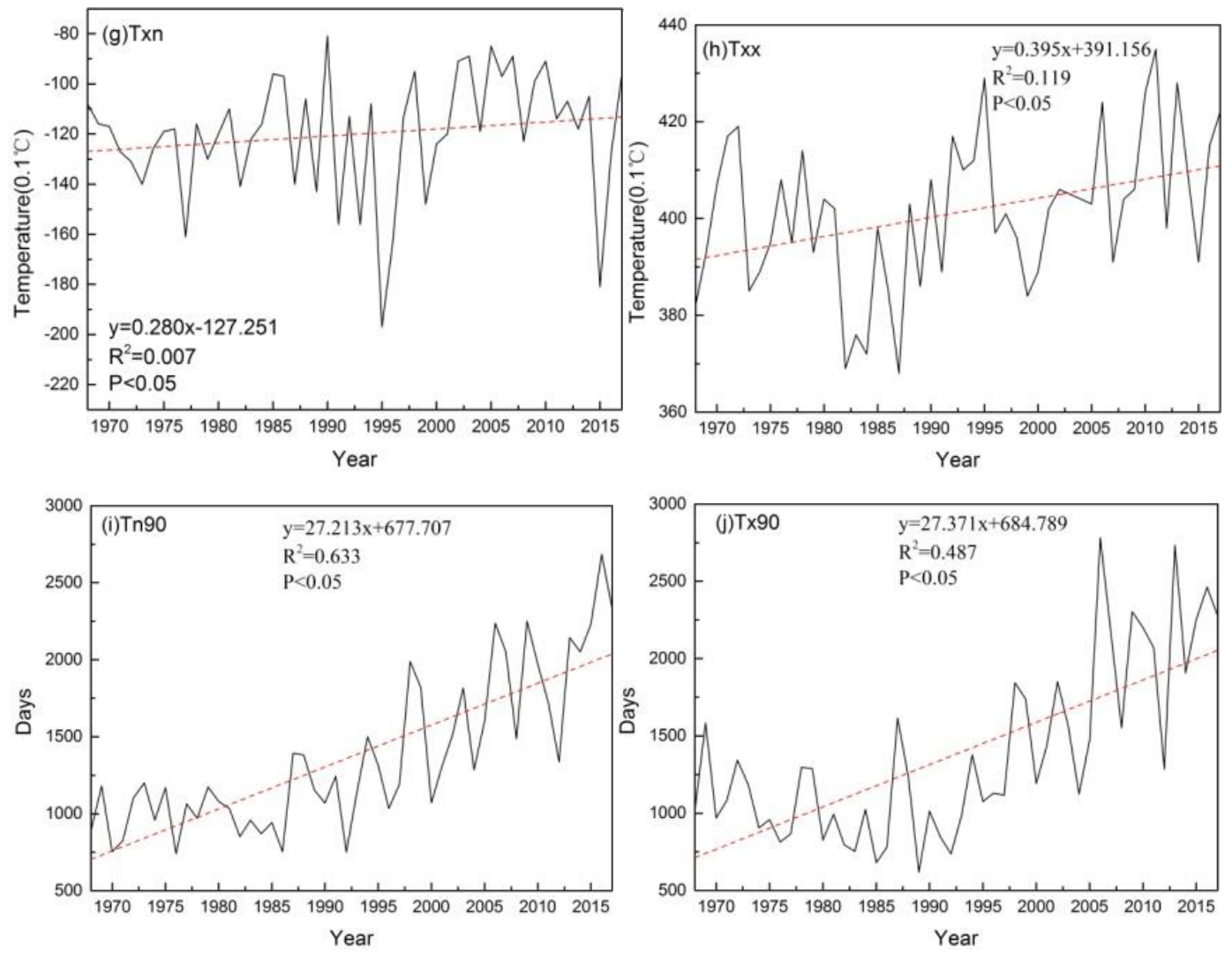

Figure 3. Interannual temporal change trends of 10 extreme temperature indices from 1968 to 2017. (a) Frost days (FD), (b) Min Tmin (Tnn), (c) Max Tmin (Tnx), (d) Cool nights (Tn10), (e) Cool days (Tx10), (f) Summer days (SU), (g) Min Tmax (Txn), (h) Max Tmax (Txx), (i) Warm nights (Tn90),(j) Warm days (Tx90)

\section{Spatial change trends}

It was also observed that Tn10 values gradually decreased from west to east. That is, the variation in the PNW (-9.0d/10a) was higher than that observed in the MSW ($8.5 \mathrm{~d} / 10 \mathrm{a})$ as well as than that in the ESB (-6.0d/10a). In addition, the largest reduction was found at the Muli Station, which value was of $-21.0 \mathrm{~d} / 10 \mathrm{a}$. The Tx10 reduction range in the MSW (-4.7d/10a) was greater than those in both, the PNW (-3.7d/10a) and the ESB (-2.6d/10a). The largest reduction was determined at the Leibo Station, which was $-11.9 \mathrm{~d} / 10 \mathrm{a}$. Comparing the values for different terrain types, the average SU increase was larger in the ESB (1.7d/10a) than those in the PNW (0.05d/10a) and MSW $(0.2 \mathrm{~d} / 10 \mathrm{a}) .13$ stations in the plateau and 4 stations in the mountainous region showed a value of 0d/10a. In the case of Txn and Txx results, most of the stations showed an increasing trend, with an amplitude of $0 \sim 0.5^{\circ} \mathrm{C} / 10 \mathrm{a}$. Also, the increasing rate value in the MSW $\left(0.41{ }^{\circ} \mathrm{C} / 10 \mathrm{a}, 0.4{ }^{\circ} \mathrm{C} / 10 \mathrm{a}\right)$ was larger than those obtained for the PNW $\left(0.31{ }^{\circ} \mathrm{C} / 10 \mathrm{a}, 0.32{ }^{\circ} \mathrm{C} / 10 \mathrm{a}\right)$ and the $\operatorname{ESB}\left(0.23^{\circ} \mathrm{C} / 10 \mathrm{a}, 0.39^{\circ} \mathrm{C} / 10 \mathrm{a}\right)$. The station with the highest increase $\left(1.09^{\circ} \mathrm{C} / 10 \mathrm{a}, 0.78^{\circ} \mathrm{C} / 10 \mathrm{a}\right)$ was the Leibo Station, which is located in the mountainous area. Growth trends of Tn90 and Tx90 gradually decreased from west to east, and the increase was the fastest in the mountainous region $(8.0 \mathrm{~d} / 10 \mathrm{a}$, and $10.3 \mathrm{~d} / 10 \mathrm{a}$, respectively). The largest increase was also found at the Muli Station in the mountainous area $(19.2 \mathrm{~d} / 10 \mathrm{a}, 17.7 \mathrm{~d} / 10 \mathrm{a})$. 

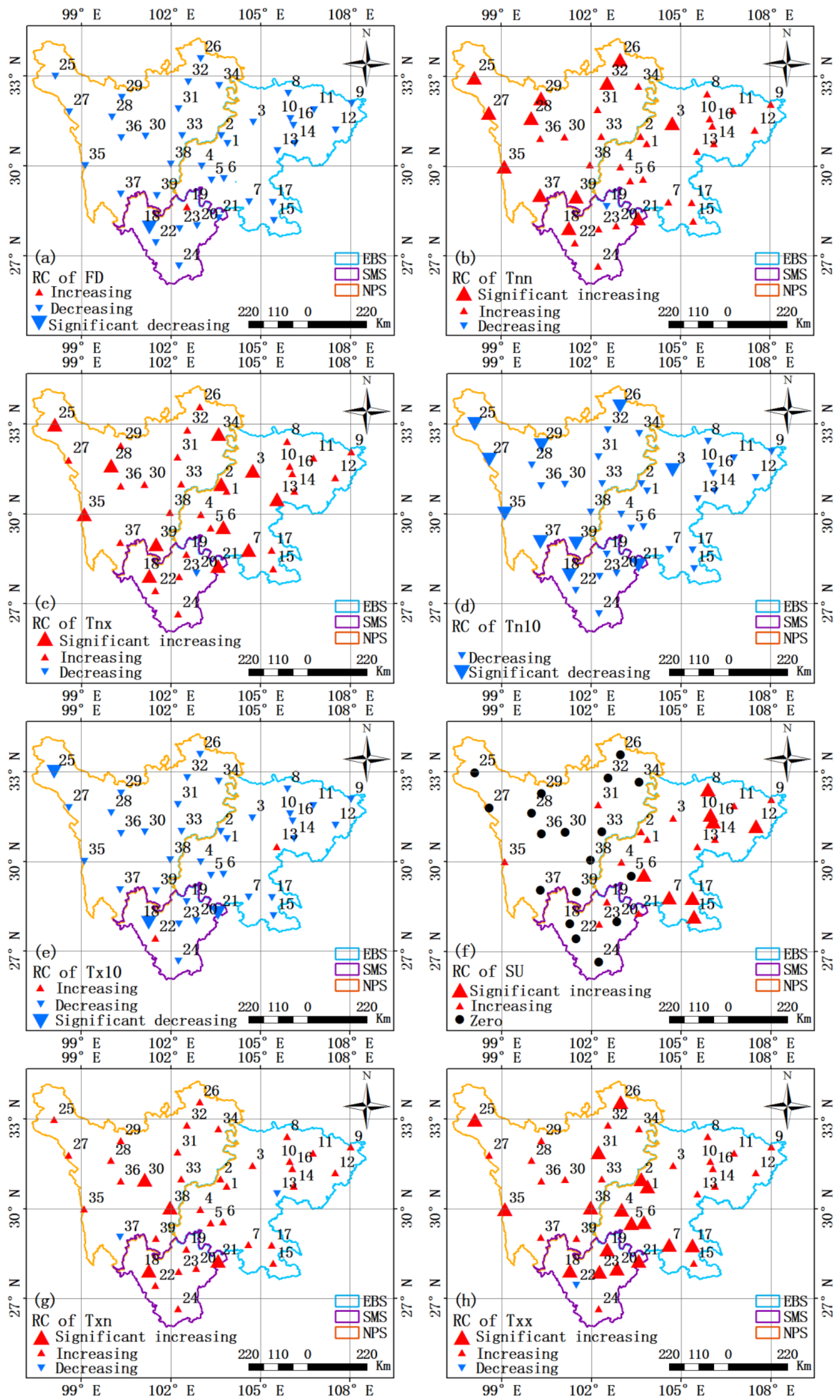

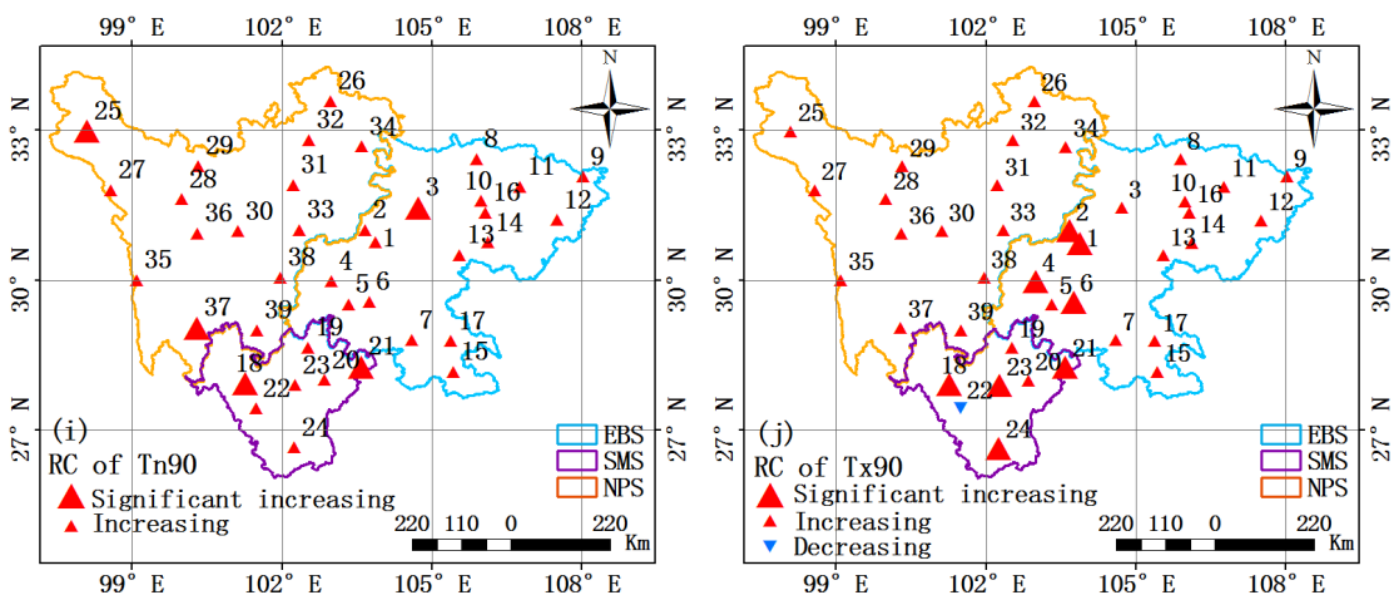

Figure 4. Spatial change trends of 10 extreme temperature indices from 1968 to 2017, (a)Frost days (FD),(b) Min Tmin (Tnn),(c) Max Tmin (Tnx),(d) Cool nights (Tn10),(e) Cool days (Tx10),

(f) Summer days (SU), (g) Min Tmax (Txn), (h) Max Tmax (Txx), (i) Warm nights (Tn90), (j)

Warm days (Tx90)

As these results showed, the extreme temperature in Sichuan exhibited an increasing trend during the past 50 years. The cold extreme events showed a warming or decreasing trend, while the warm extreme events showed a warming or increasing tendency. The variation trend in the west was more significant than that in the east, that is, the warming amplitude was higher in the PNW and MSW than in ESB. Particularly, the mountain to basin transition regions (Muli and Yuexi Station), as well as highaltitude areas were the most affected by global warming.

\section{Mutation characteristics}

Climate modifications are identified as abrupt changes in statistical spatio-temporal features, and can be represented by mutation points (Fu and Wang, 1992). To ensure the scientificity and accuracy of this research, the M-K and sliding T tests (subseries length 5) were simultaneously used for cross-validation. The purpose is to exclude false mutation points, which are identified by one of the two above-mentioned methods. This way, the reliability of the mutation analysis results is enhanced. Table 3 shows the results for the $\mathrm{M}-\mathrm{K}$ and the sliding $\mathrm{T}$ tests, as well as wavelet analysis for extreme temperature indices during the period of 1968 to 2017. Due to space constraints, only selected resulting diagrams are shown herein. Tnn diagrams for cold indices as well as SU diagrams for the warm indices are presented in Figure 5. It is important to state that other analysis yield similar results.

As shown in Figure 5a, the UF curve for Tnn showed overall increasing values over time. However, considering time stages, a decreasing trend was observed before the 1980s. Later, between the early 1980s and the mid-1990s, an increasing tendency occurred, followed by a slight decline. Finally, after the year of 2000, a growing trend was observed. The change was significant after $2010(\mathrm{P}<0.05)$. The two UF and UB statistics intersected in the year of 2002, which indicated the starting mutation time and increasing. As data show in Figure $5 c$, the Tnn curve was both, concave and convex in shape; however, no mutation point appeared. Combining the results of the two tests, it was judged that there was no mutation year for Tnn, however this index steadily increased after the year of 2000. In Figure 5b, the UF curve for SU showed an 
increasing trend before the $1980 \mathrm{~s}$, while between the $1980 \mathrm{~s}$ and the $21^{\text {st }}$ century the tendency decreased. It was also observed that, before and after 1990, such decline was significant. In addition, after the $21^{\text {st }}$ century SU increased, especially after 2012 when the change was significant $(\mathrm{P}<0.05)$. The UF and UB statistics corresponding to SU intersected in 2009. This point indicated starting time of increasing change and mutation. As shown in Figure $5 d$, the t statistic exceeded the 0.05 significance level test in 1979. Since the $t$ statistic is greater than zero, it indicated that SU experienced a significant mutation from lower to higher values in 1979. However, as two test crossvalidation results indicated, no year for SU mutation occurred.
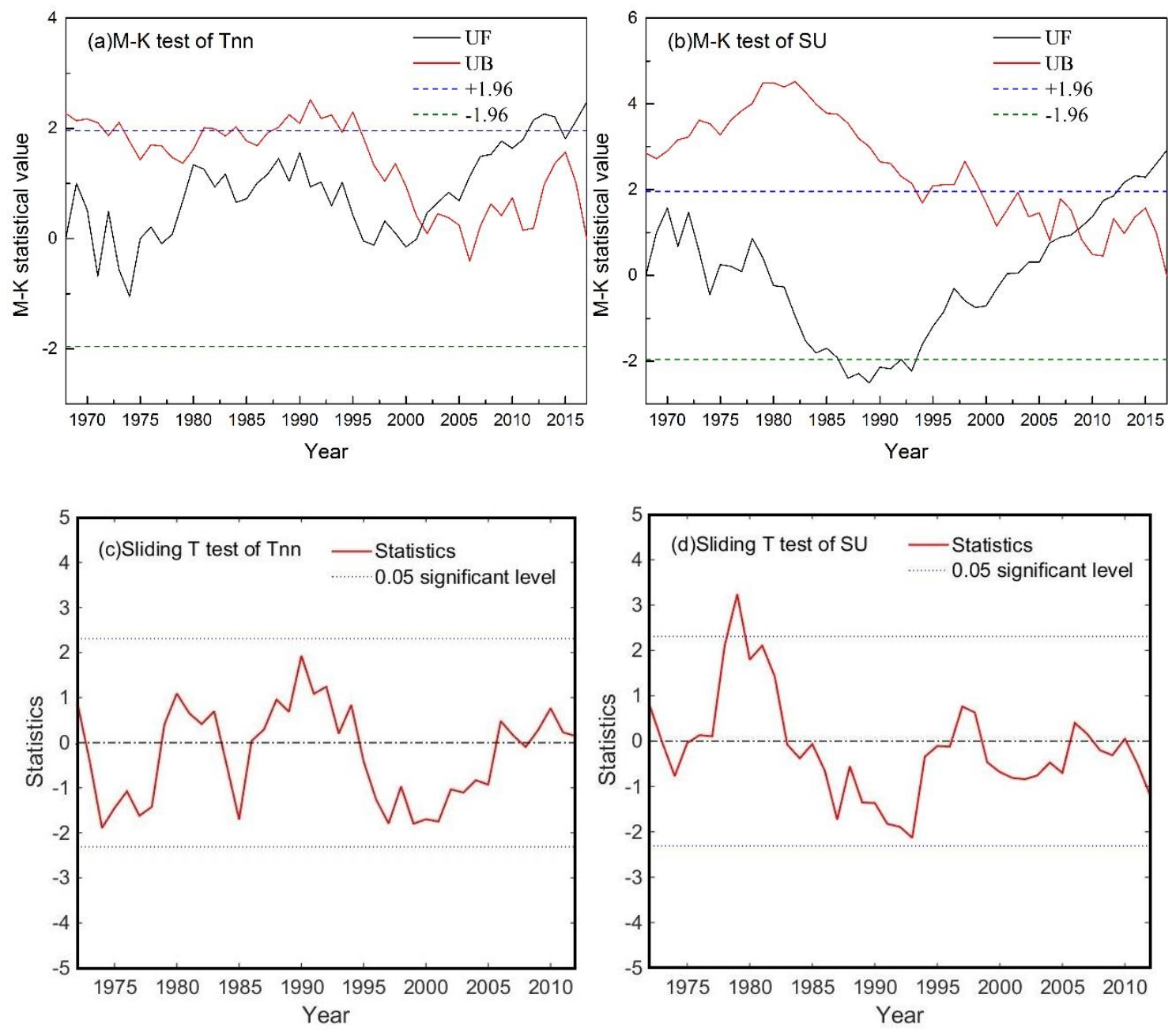

Figure 5. $M-K$ and sliding $T$ test of Tnn and $S U$, (a) $M-K$ test of Tnn, (b) $M-K$ test of $S U$, (c) Sliding T test of Tnn, (d) Sliding T test of SU

Table 3 displays the results of mutation points identified for all extreme temperature indices by the $\mathrm{M}-\mathrm{K}$ and sliding $\mathrm{T}$ test. Taken together, except for the mutation year of Tnx in 1995, there were no significant mutation years in the other extreme temperature indices during the past 50 years. It was also determined that there was no significant mutation in extreme temperatures. However, increasing temperature trends were noticeable in the 1980 s and the early $21^{\text {st }}$ century. 


\section{Periodic characteristics}

Considering Tnn and SU as references, a detailed analysis in terms of wavelet periodic characteristics were performed (Fig. 6). Figure 6a, $d$ shows the corresponding normalized time series. The threshold for the Tnn time series varied within \pm 2.5 and changes were not significant. The threshold for the SU time series was about \pm 2 , with only a significant increase in the normalized value for the year of 2006. Figure $6 b$, $e$ shows the wavelet power spectrum, which represents the fluctuation magnitude of the time series on the given wavelet scale and within a given time domain. The larger the wavelet power, the greener the color. The inverted coneshaped lines in the figure correspond to the influence lines. The portion of the wavelet power spectrum below these influence lines indicates the marginal influence effect. Also, periodic features exhibit a greater uncertainty. Closed curves in the spectrum are related to regions with high power values. Tnn and SU closed regions corresponded to periods of significant interannual variation, which were all 2-6 years in length. Intense periodic change effects on this scale occurred in 1968 1980 and 1982 2017 for Tnn, while for SU happened from 1968 to1982 and from 1991 to 2017. Since time series variances of many physical quantities increase with time (red noise features), these red noises can be used as background when performing wavelet spectrum analysis. Figure $6 c, f$ represents the full wavelet spectrum obtained when significance test is applied to the wavelet spectrum. When the solid lines (wavelet power spectrum curve) are smaller than the dotted line (this line represents the 0.05 significance level), it means that the periodic feature corresponding to this region passed the 0.05 significance level test. Thus, according to the data obtained, every Tnn and SU period that passed the significance test previously mentioned was all 2-6 years. In addition, when the period was 6 years long, the energy and oscillation were the strongest. As shown in the wavelet analysis results, between all the extreme temperature indices included in Table 3, the Txn period that passed the significance test was also the one which was 2-6 years. However, FD and Tn10 did not show significant wavelet periods. The periods for Tnx and Txx that passed the significance test were all 24 years, and for Tx10, Tn90 and Tx90 were all 3-4 years.

Table 3. $M-K$ test, sliding $T$ test and wavelet analysis results of 10 extreme temperature indices

\begin{tabular}{c|c|c|c|c}
\hline Indices & M-K test & Sliding T test & $\begin{array}{c}\text { Mutation } \\
\text { years }\end{array}$ & $\begin{array}{c}\text { Wavelet } \\
\text { significant periods }\end{array}$ \\
\hline FD & 1993 & $1984,1985,1986$ & No & No \\
Tnn & 2002 & No & No & $2 \sim 6$ \\
Tnx & $1969,1973,1976,1979,1992,1995,2002$ & $1988,1990,1995,2008$ & 1995 & $2 \sim 4$ \\
Tn10 & 1990 & 1976,2010 & No & No \\
Tx10 & $1969,2005,2006,2007$ & No & No & $3 \sim 4$ \\
SU & 2009 & 1979 & No & $2 \sim 6$ \\
Txn & $1985,1986,1988,1990,1997$ & No & No & $2 \sim 6$ \\
Txx & 2005 & $1980,1981,1987,1989,1991,1995,1996,2000,2001$ & No & $2 \sim 4$ \\
Tn90 & 2015 & $1980,1981,2009,2010,2011$ & No & $3 \sim 4$ \\
Tx90 & $1970,2005,2006,2012,2014$ & No & No & $3 \sim 4$ \\
\hline
\end{tabular}



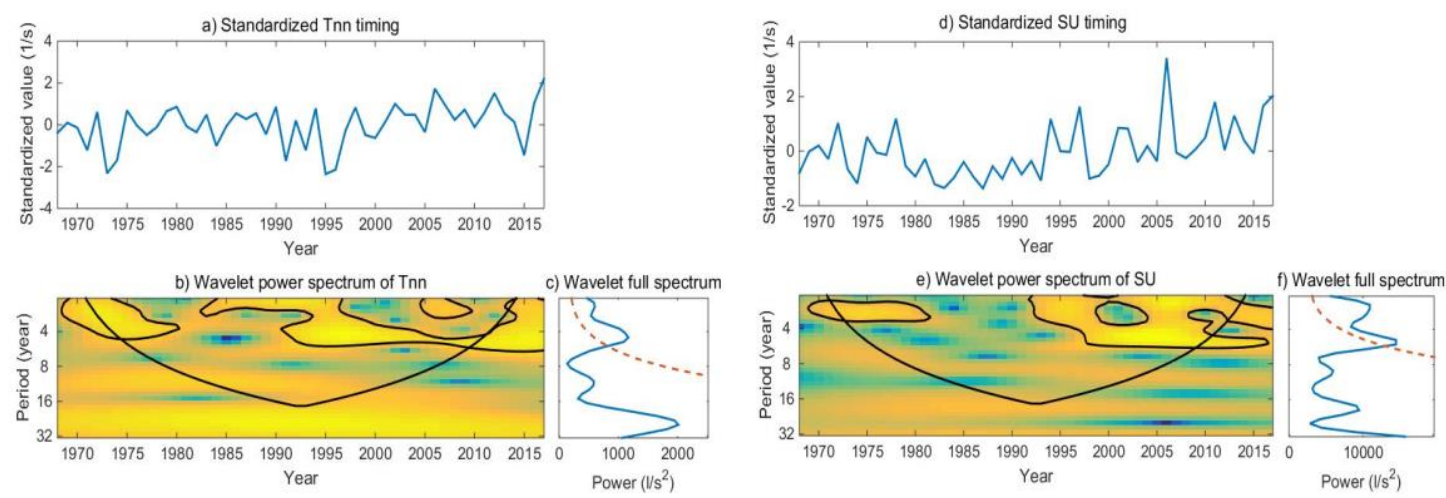

Figure 6. Wavelet analysis of Tnn and SU. (a) Standardized Tnn timing, (b) Wavelet power spectrum of Tnn, (c) Wavelet full spectrum of Tnn, (d) Standardized SU timing, (e) Wavelet power spectrum of $S U,(f)$ Wavelet full spectrum of $S U$

\section{Spatial and temporal variation characteristics of extreme precipitation indices}

\section{Interannual temporal variations}

Considering the integrity and uniformity of data, 5 stations, namely, Batang (No.35), Huili (No.24), Guangyuan (No.8), Daxian (No.12), and Xuyong (No.15) where the precipitation data were incomplete, were excluded when analyzing extreme precipitation events in Sichuan. Therefore, only 34 stations were included in this type of analysis. As observed from the interannual variation trend of 9 extreme precipitation indices (Fig. 7), extreme precipitation occurred in the past 50 years; in addition, in the days of these events larger fluctuations were observed. Overall trend variation was not obvious, though. Also, R10, R95p, R99p and SDII displayed a mild increasing trend, with interannual variation tendency rate of $0.9 \mathrm{~d} / 10 \mathrm{a}, 79.5 \mathrm{~mm} / 10 \mathrm{a}$, $160.6 \mathrm{~mm} / 10 \mathrm{a}$ and $0.05(\mathrm{~mm} / \mathrm{d}) / 10 \mathrm{a}$, respectively. All remaining indices (CDD, CWD, R20, R50, and PRCPTOT) exhibited decreasing tendencies, with inter-decadal variation rates of $-0.8 \mathrm{~d} / 10 \mathrm{a},-0.4 \mathrm{~d} / 10 \mathrm{a},-0.1 \mathrm{~d} / 10 \mathrm{a},-0.5 \mathrm{~d} / 10 \mathrm{a}$ and $-39.5 \mathrm{~mm} / 10 \mathrm{a}$, respectively. Inter-decadal variation tendency rates of every station analyzed in this research passed the 0.05 significance level test. On an overall perspective, the interannual variation of the extreme precipitation indices in Sichuan was not significant for the past 50 years. Nevertheless, some violent fluctuations occurred. Moreover, data also indicated that a regional peak appeared every 5 years.

\section{Spatial change trends}

Figure 8 shows the spatial distribution of extreme precipitation indices at 34 stations during the past 50 years. In the PNW area, CDD mostly showed a decreasing trend, with an average variation of $-0.81 \mathrm{~d} / 10 \mathrm{a}$. In contrast, in the MSW and ESB areas, this same index showed an increasing trend, with an average variation of $1.57 \mathrm{~d} / 10 \mathrm{a}$ and $0.82 \mathrm{~d} / 10 \mathrm{a}$, respectively. In every Sichuan region, except for 8 stations, CWD decreased. Among all geographical areas analyzed, the average PNW variation rate was of $0.04 \mathrm{~d} / 10 \mathrm{a}$, and those corresponding to MSW and ESB were $-0.25 \mathrm{~d} / 10 \mathrm{a}$ and $0.18 \mathrm{~d} / 10 \mathrm{a}$, respectively. R10 and R20 PNW showed an increasing trend $(0.55 \mathrm{~d} / 10 \mathrm{a}$, and $0.14 \mathrm{~d} / 10 \mathrm{a}$, in that order), and the R50 variation rate at 12 stations was of $0 \mathrm{~d} / 10 \mathrm{a}$. Thus, R50 for the PNW region basically remained unchanged $(0.007 \mathrm{~d} / 10 \mathrm{a})$. R10, R20, 
and R50 variation rates for the MSW area were of $-0.03 \mathrm{~d} / 10 \mathrm{a}, 0.12 \mathrm{~d} / 10 \mathrm{a}$, and $0.10 \mathrm{~d} / 10 \mathrm{a}$, respectively. Values decreased in the ESB, where R10, R20 and R50 reduction rates were $-0.40 \mathrm{~d} / 10 \mathrm{a},-0.22 \mathrm{~d} / 10 \mathrm{a}$, and $-0.11 \mathrm{~d} / 10 \mathrm{a}$, in that order. $\mathrm{R} 95 \mathrm{p}$ and R99p showed an increasing trend, and PRCPTOT decreased. In general, the average variation rates of these three indices in PNW were $9.97 \mathrm{~mm} / 10 \mathrm{a}, 6.70 \mathrm{~mm} / 10 \mathrm{a}$, and $12.64 \mathrm{~mm} / 10 \mathrm{a}$, respectively; those in the MSW region were $7.85 \mathrm{~mm} / 10 \mathrm{a}$, $4.68 \mathrm{~mm} / 10 \mathrm{a}$, and $1.37 \mathrm{~mm} / 10 \mathrm{a}$, in that order. However, the variation trend in ESB was slightly different (variation rates were $-7.64 \mathrm{~mm} / 10 \mathrm{a}, 2.06 \mathrm{~mm} / 10 \mathrm{a}$, and $-15.56 \mathrm{~mm} / 10 \mathrm{a}$, correspondingly). SDII mostly increased in PNW and MSW (variation rates were $0.008(\mathrm{~mm} / \mathrm{d}) / 10 \mathrm{a}$ and $0.003(\mathrm{~mm} / \mathrm{d}) / 10 \mathrm{a}$, respectively). However, a decreasing trend was observed in ESB, where the variation rate was $-0.005(\mathrm{~mm} / \mathrm{d}) / 10 \mathrm{a}$. As shown, variation amplitude was rather small. According to the previous analysis, there were noticeable spatial and regional differences in the extreme precipitation events in Sichuan during the past 50 years. Precipitation increased in PNW and MSW, and significantly decreased in ESB. In particular, precipitations registered in the Ya'an, Emeishan, and Leshan Station where the precipitation used to be very abundant, showed a decrease. Among different regions, the precipitation as well as extreme precipitation events in PNW and MSW considerably increased. In detail, the number of heavy rain, rainstorm and very heavy precipitation events in the plateau increased. There was also arise in the number of extreme precipitation events in the mountainous regions. However, the amplitude was not as large as that observed in the plateau. The basin, however, displayed a drying trend with decreased precipitation, and the extreme precipitation was also reduced.
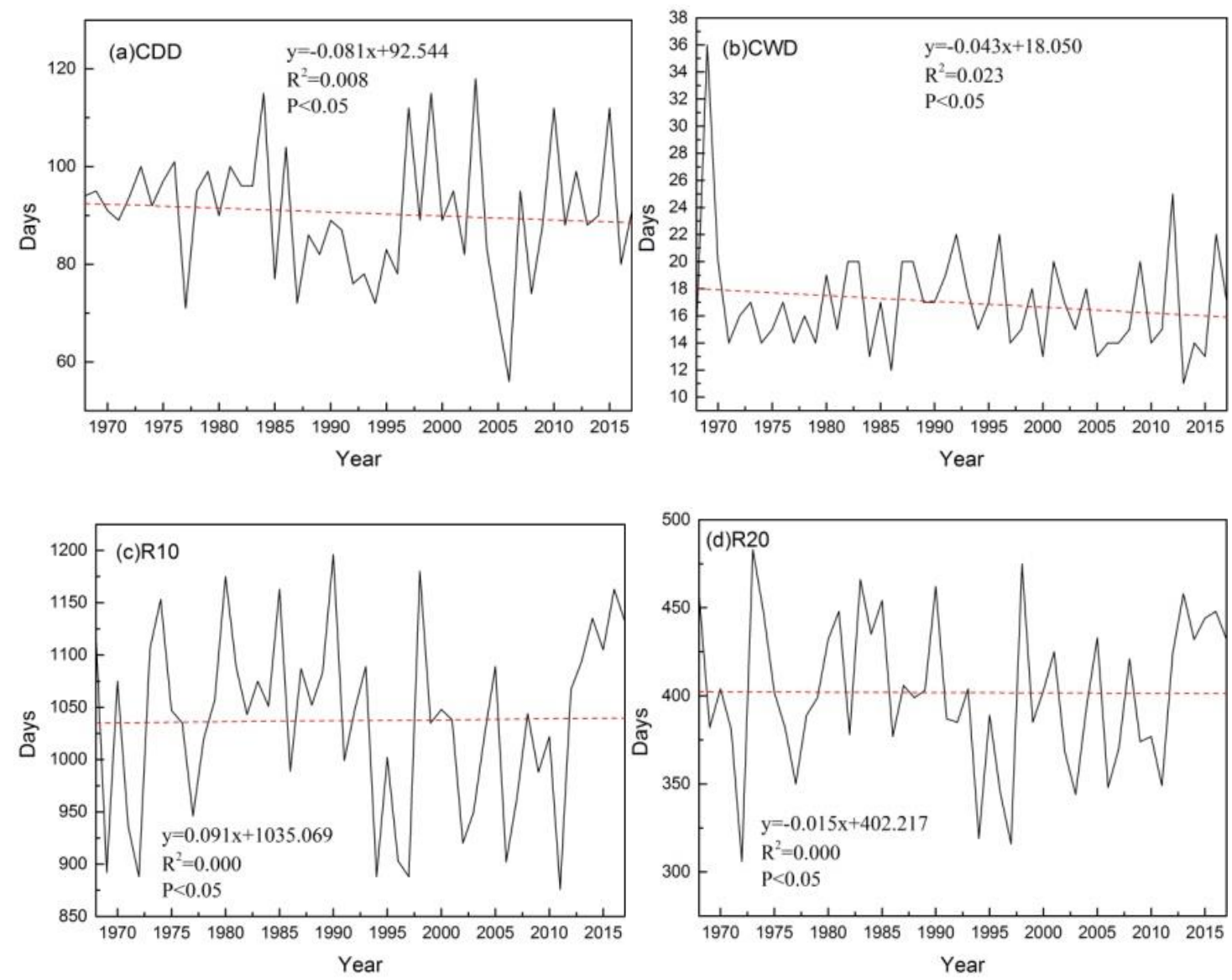

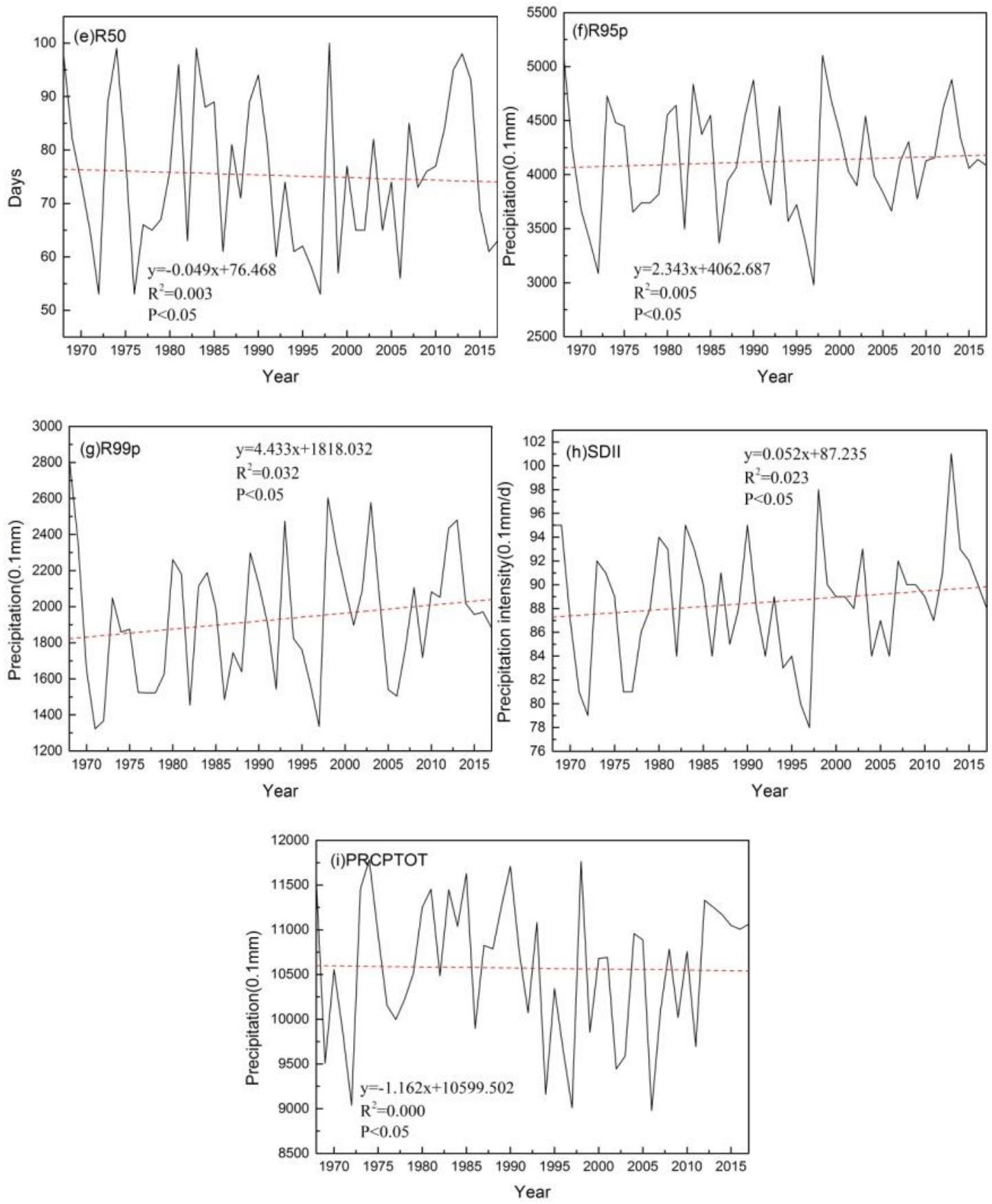

Figure 7. Interannual temporal change trends of 10 extreme precipitation indices from 1968 to 2017. (a) Consecutive dry days (CDD), (b) Consecutive wet days (CWD), (c) Number of heavy precipitation days (R10), (d) Number of very heavy precipitation days (R20), (e) Number of rainstorm days $(R 50)$, $(f)$ Very wet days $(R 95 p),(g)$ Extremely wet days $(R 99 p)$, $(h)$ Simple daily intensity index (SDII), (i) Annual total wet-day precipitation (PRCPTOT)

\section{Mutation characteristics}

Table 4 shows the results when extreme precipitation indices from 1968 to 2017 were assayed using the M-K test, sliding $\mathrm{T}$ test, and wavelet analysis. The process was similar to that applied to the extreme temperature indices. Only the CWD and 
PRCPTOT test results were analyzed as examples. Figure 9 shows the M-K test and sliding $\mathrm{T}$ test statistical diagrams for these two indices. As our results showed, the CWD UF curve displayed an increasing trend during the period going from the 1980s to the early $21^{\text {st }}$ century; also, in 1996 this curve over passed the 0.05 significance level line (Fig. 9a). CWD significantly increased in 1996, and after this point, it started decreasing. Moreover, UF and UB statistics intersected in 2013 and 2015. The CWD ttest statistic showed a wavy fluctuation, where no significant values or mutation points occurred (Fig. 9c). Combining the results of the two tests, it was concluded that there was no mutation year. For PRCPTOT (Fig. 9b), the intersections between the UF and UB statistics first occurred in 1973, and later in 1991, 2012, and 2014, successively. Combining this with the sliding $\mathrm{T}$ test results for the mutation points (Fig. 9d), it was verified that these were true in 1991. Due to limited space, other indices do not be analyzed in detail. A summary of the results is shown in Table 4. Taken together, CDD, CWD, R10, R20, and SDII extreme precipitation indices did not show significant mutation years in the past 50 years. In addition, mutation years for R50, R95p, R99p, and PRCPTOT occurred in 1980, 2010, 2004, and 1991, respectively. This means that mutation years corresponding to heavy and very heavy precipitation events mainly appeared in the 1980 and the early $21^{\text {st }}$ century.

Table 4. M-K test, sliding $T$ test and wavelet analysis results of 9 extreme precipitation indices

\begin{tabular}{c|c|c|c|c}
\hline Indices & M-K test & Sliding T test & $\begin{array}{c}\text { Mutation } \\
\text { years }\end{array}$ & $\begin{array}{c}\text { Wavelet significant } \\
\text { periods }\end{array}$ \\
\hline CDD & $1970,1971,1984,1985,1986$ & $1996,2003,2008$ & No & $2 \sim 4$ \\
CWD & 2013,2015 & No & No & $2 \sim 5$ \\
R10 & $1973,1975,1979,1989,1990,1991,2015$ & $1992,2011,2012$ & No & $2 \sim 6$ \\
R20 & $1974,1980,1981,1985,2015$ & $1979,2011,2012$ & No & $2 \sim 6$ \\
R50 & $1968,1973,1980,1981,1982,1985,2010,2015$ & $1979,1980,1991,1992,2008,2009$ & 1980 & $2 \sim 7$ \\
R95p & $1981,1983,2010$ & $2009,2010,2011$ & 2010 & $2 \sim 7$ \\
R99p & $1997,2001,2003,2004,2008$ & $1979,2004,2009,2010,2011$ & 2004 & $2 \sim 6$ \\
SDII & $1969,1981,1983,1985,2007$ & $1979,1991,1997$ & No & $2 \sim 7$ \\
PRCPTOT & $1973,1991,2012,2014$ & $1979,1980,1991,2011$ & 1991 & $2 \sim 6$ \\
\hline
\end{tabular}

\section{Periodic characteristics}

As previously mentioned, detailed analysis was performed for CWD and PRCPTOT test results in terms of wavelet cycle features (Fig. 10). Figure 10a, $d$ shows the normalized time series. The threshold for CWD and PRCPTOT time series was about \pm 2 , and the normalized CWD value significantly increased in 1969. Figure 10b, $e$ shows the wavelet power spectrum. The CWD closed region corresponded to a period of 2-7 years and that of PRCPTOT corresponded to a period of 2-8 years. In other words, intervals of significant interannual variation were of 2-7 and 2-8 years for CWD and PRCPTOT, correspondingly. Strong concentration periodic change effects on this scale appeared in the intervals 1968 1975, 1977 2002, and 2006 2017 for CWD. Also, in the case of PRCPTOT, time domains were 1968 1980 and 1982 2012. Red noises 
were used as background for the analysis of the wavelet spectrum. Figure 10c, $f$ presents the full wavelet spectrum corresponding to the CWD and PRCPTOT period that passed the significance test. These periods were 2-4 and 2-6 years, respectively. The interval with the strongest wavelet energy was 4 years in length and that of PRCPTOT was 3 years. As indicated in Table 4 that corresponds to the wavelet analysis of all extreme precipitation indices, periods where R10, R20, and R99p passed the significance test were also from 2-6 years. In the case of R50, R95p and SDII, interval was 2-7 years, and for CDD, it was 2-4 years.
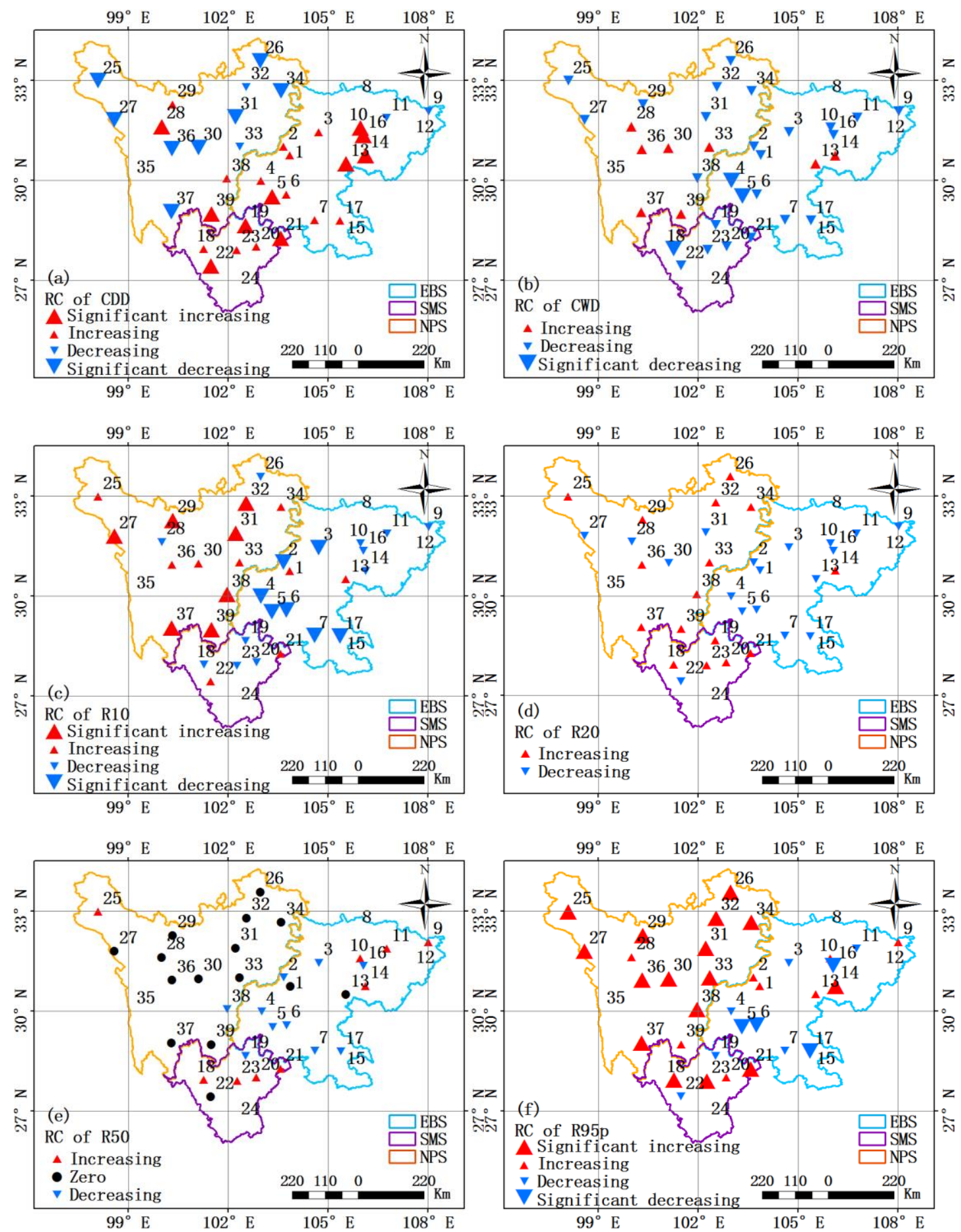

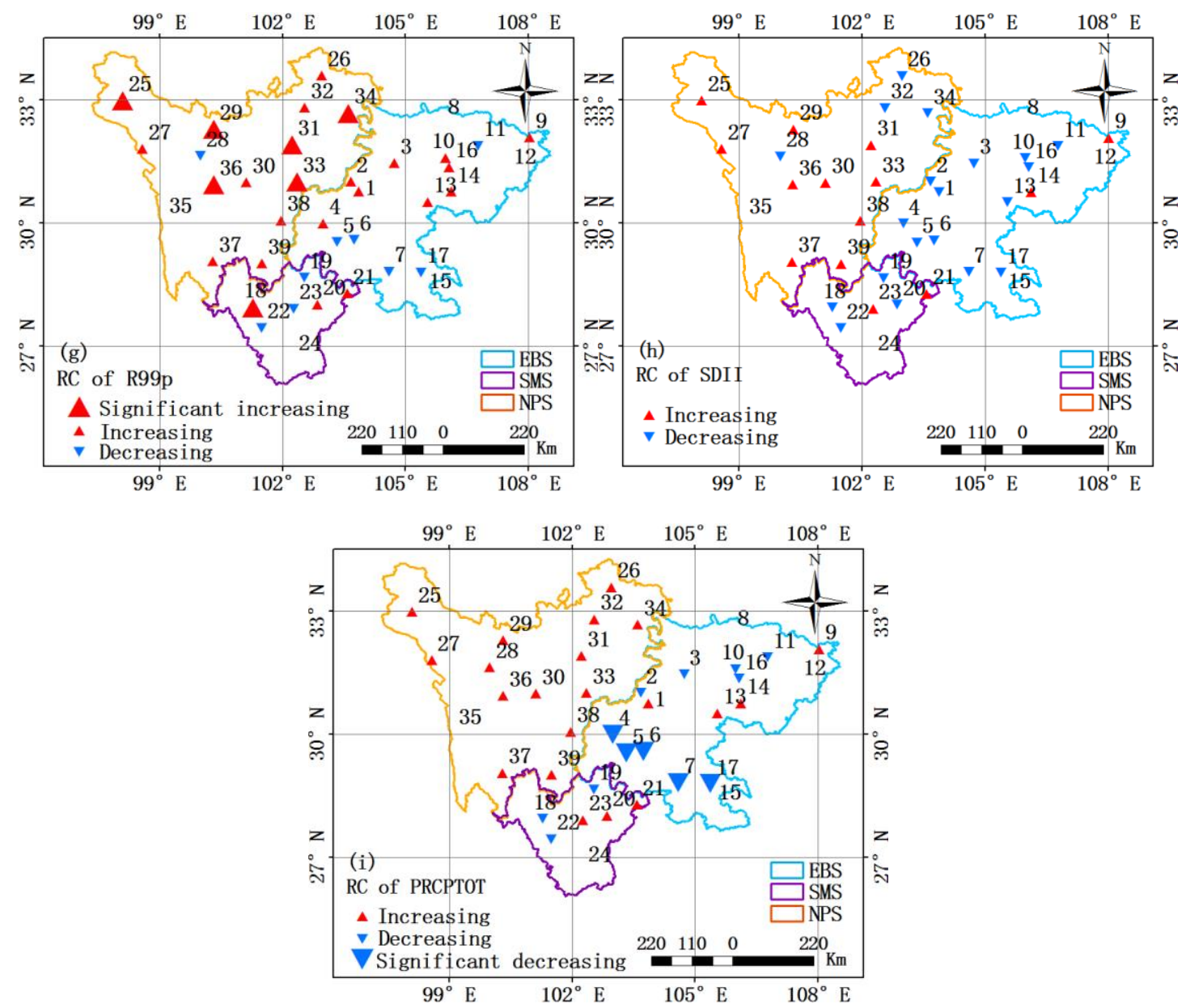

Figure 8. Spatial change trends of 9 extreme precipitation indices from 1968 to 2017. (a)

Consecutive dry days (CDD), (b) Consecutive wet days (CWD), (c) Number of heavy

precipitation days $(R 10)$, (d) Number of very heavy precipitation days $(R 20),(e)$ Number of rainstorm days (R50), $(f)$ Very wet days $(R 95 p),(g)$ Extremely wet days $(R 99 p)$, ( $h$ ) Simple daily intensity index (SDII), (i) Annual total wet-day precipitation (PRCPTOT)

\section{Relationship between extreme climate index and geographical factors}

According to the spatial distribution and regional difference analyses for extreme climate indices, it was demonstrated that topographical changes greatly affect extreme climate changes in the Sichuan Province. This region is roughly limited by the Guangyuan-Jiangyou-Dujiangyan-Yingjing-Muli line, and the topography is high to the northwest and low to the southeast. Extreme climate indices changes are highly related to longitude, latitude and altitude. In this research, the influence of these parameters on extreme climate indices was discussed (Table 5). Correlation analysis showed that Tnn, Tnx, SU, Txn and Txx were negatively correlated to elevation $(\mathrm{P}<0.01)$, and positively to longitude $(\mathrm{P}<0.05)$. Tnn, Tnx, Txn and Txx were negatively correlated to latitude; however, only Tnn and Txn passed the test at the 0.05 significance level. This indicated that the higher the altitude, the lower the longitude and the lower the latitude, the closer to the southwestern mountain area of Sichuan, the greater the change of the given extreme index value. Warmer extreme minimum and extreme maximum temperatures mainly occurred in the western alpine plateau area, and the warming range was larger as 
compared to that of the eastern basin. FD and Tn10 were positively correlated to elevation $(P<0.01)$ and latitude $(P<0.05)$, and negatively to longitude $(P<0.05)$. This indicated that the higher the altitude, the higher the latitude and the lower the longitude, the closer the alpine plateau area in northwest Sichuan, the greater the change of extreme index value, the greater the reduction of extreme cold events in the west, and the smaller the reduction in the eastern basin. There was no significant correlation between other extreme climate indices (Tx10, Tn90 and Tx90) and geographical factors. Of the extreme precipitation indices, CDD, CWD and SDII positively correlated to elevation $(\mathrm{P}<0.01)$, and negatively to longitude (except SDII, others passed the test at the 0.05 significance level); other indices (R10, R20, R50, R95p, R99p, PRCPTOT) negatively correlated to elevation and latitude, and positively to longitude, and most of them passed the test at the 0.05 significance level. This indicated that the higher the altitude, the lower the longitude and the higher the latitude, the closer the plateau and mountainous area in west Sichuan, the greater the change of extreme index value. These results were consistent with those of the spatial distribution for the extreme climate indices previously mentioned. Terrain characteristics affect spatial variation of extreme climate indices in Sichuan Province.

Table 5. Correlation analysis between extreme climate indices and geographical factors

\begin{tabular}{|c|c|c|c|c|c|c|c|}
\hline $\begin{array}{c}\text { Extreme } \\
\text { temperature } \\
\text { indices }\end{array}$ & Longitude & Latitude & Elevation & $\begin{array}{c}\text { Extreme } \\
\text { precipitation } \\
\text { indices }\end{array}$ & Longitude & Latitude & Elevation \\
\hline FD & $-0.465 * *$ & $0.444 * *$ & $0.940 * *$ & $\mathrm{CDD}$ & $-0.380 *$ & -0.231 & $0.479 * *$ \\
\hline Tnn & $0.452 * *$ & $-0.447 * *$ & $-0.899 * *$ & CWD & $-0.510 * *$ & 0.036 & $0.733 * *$ \\
\hline $\operatorname{Tnx}$ & $0.518 * *$ & -0.263 & $-0.982 * *$ & $\mathrm{R} 10$ & 0.147 & $-0.402 *$ & -0.213 \\
\hline $\operatorname{Tn} 10$ & $-0.330^{*}$ & $0.344^{*}$ & $0.658 * *$ & R20 & $0.402 *$ & $-0.372 *$ & $-0.640 * *$ \\
\hline Tx10 & -0.193 & -0.149 & 0.206 & $\mathrm{R} 50$ & $0.506^{* *}$ & -0.078 & $-0.720 * *$ \\
\hline SU & $0.362 *$ & 0.009 & $-0.702 * *$ & R95p & $0.545^{* *}$ & -0.180 & $-0.820 * *$ \\
\hline Txn & $0.338 *$ & $-0.397 *$ & $-0.753 * *$ & R99p & $0.548 * *$ & -0.122 & $-0.838 * *$ \\
\hline Txx & $0.439 * *$ & -0.198 & $-0.891 * *$ & SDII & -0.266 & $0.540 * *$ & $0.517 * *$ \\
\hline $\operatorname{Tn} 90$ & -0.028 & 0.203 & 0.199 & PRCPTOT & $0.417 *$ & -0.336 & $-0.578 * *$ \\
\hline Tx90 & 0.023 & $0.387 *$ & -0.012 & & & & \\
\hline
\end{tabular}

**Passing the test at the 0.01 significance level $(\mathrm{P}<0.01)$. *Passing the test at the 0.05 significance level $(\mathrm{P}<0.05)$
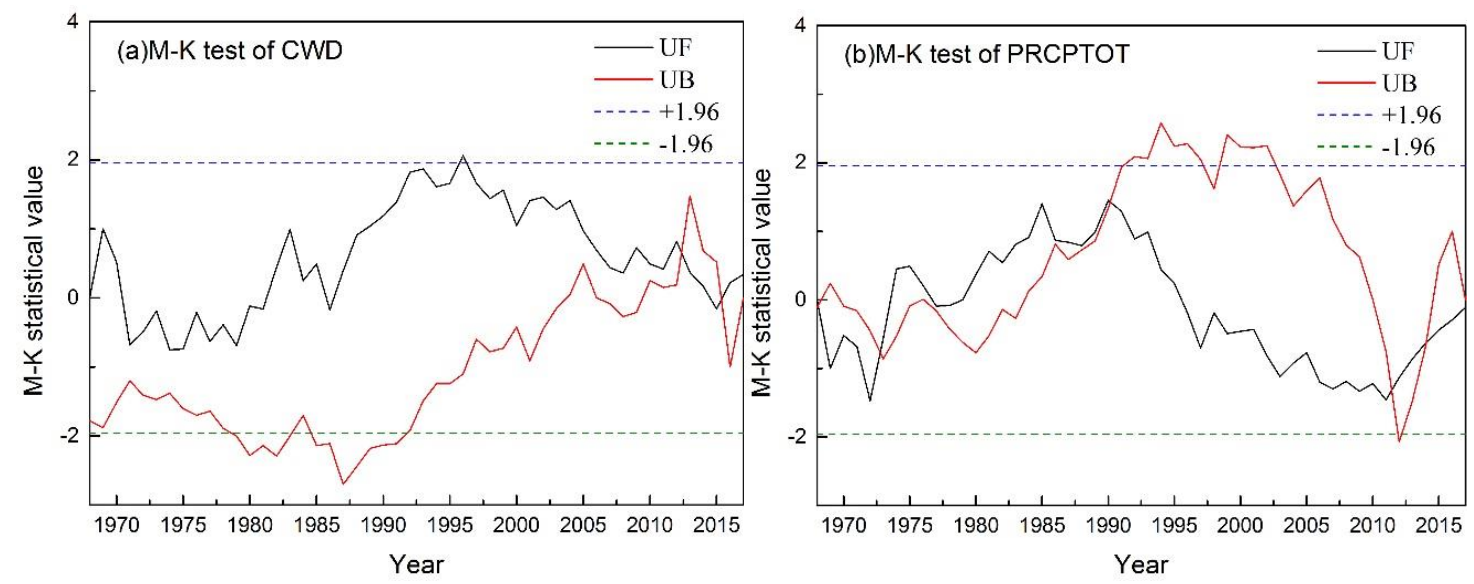

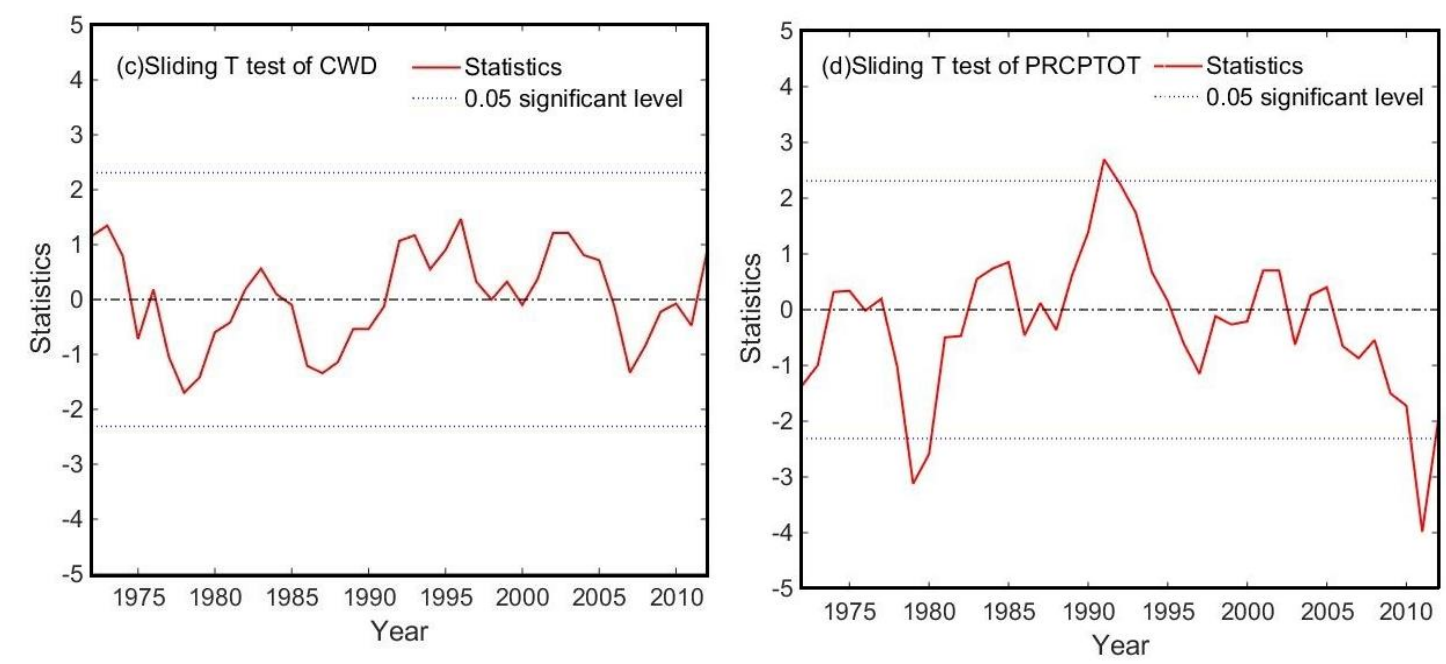

Figure 9. $M-K$ and sliding $T$ test of $C W D$ and PCRPTOT. (a) $M-K$ test of $C W D$, (b) $M-K$ test of PCRPTOT, (c) Sliding T test of CWD, (d) Sliding T test of PCRPTOT
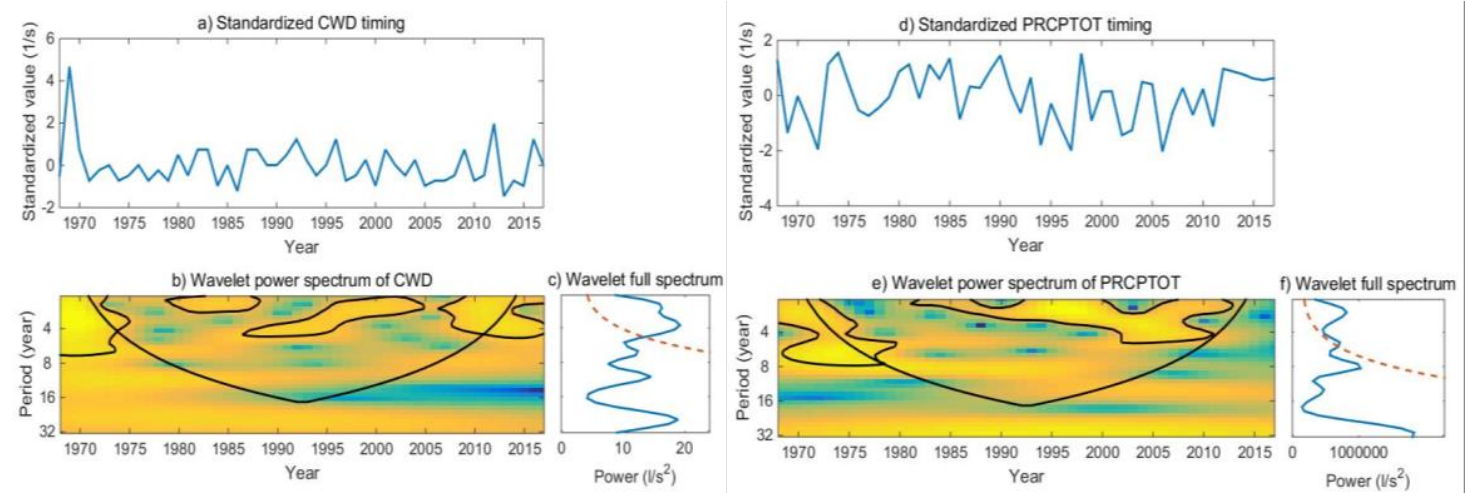

Figure 10. Wavelet analysis of CWD and PCRPTOT. (a) Standardized CWD timing, (b) Wavelet power spectrum of CWD, (c) Wavelet full spectrum of CWD, (d) Standardized PCRPTOT timing, (e) Wavelet power spectrum of PCRPTOT, $(f)$ Wavelet full spectrum of PCRPTOT

\section{Change trends of extreme temperature and precipitation in the future}

In order to analyze future variation trends of extreme climate indices in Sichuan, Hurst exponents were calculated for every 19 extreme climate indices, and the results are shown in Table 6. As data indicated, Tn10, Tx10, SU, and Tn90 Hurst exponents were all obtained with values above 0.5 , which indicated the hidden long-term trend in the time series, i.e., strong long-term memory and a positive effect as well as a high probability of continuing the current trend. The Hurst FD, Txx, R10, R20, R50, and PRCPTOT exponents were all smaller than 0.5, indicating that the time series was either not persistent or persistent in the inverse state. According to these results, they might well mark the beginning of weakened memory and inversion. The Hurst Tnn, Tnx, Txn, Tx90, CDD, CWD, R95p, R99p, and SDII exponents were close to 0.5, indicating that the variation approached a random series, and the accuracy of a future trend prediction decreased to a certain extent. Of all extreme climate indices, the Hurst exponent for 
Tn90 was the largest (0.802), and that of the PRCPTOT was the smallest (0.320). This was significantly greater (less) than the critical value of the random walk hypothesis. This means that an apparent positive (negative) continuity and fractal structure resulted in the time series. This is, an increment in the past might represent an increment (decrement) in the future. By combining the Hurst exponent analysis and the interannual variation trends for the 19 extreme climate indices (Figs. 3 and 7), it was determined that among all extreme temperature indices in Sichuan, FD, SU, and Tn90 may increase in the future. Conversely, Tn10, Tx10, and Txx may decrease, i.e., as a whole, extreme cold events will decrease and extreme warm events will increase. Of all extreme precipitation indices, R20, R50 and PRCPTOT may increase, while R10 may decrease. That is, it is very likely that the precipitation and the number of heavy precipitation and rainstorm events will increase in the future, and that both, the extreme temperature and extreme precipitation events of the Sichuan Province, will increase in the future.

Table 6. Hurst exponents of 19 extreme climate indices

\begin{tabular}{c|c|c|c}
\hline $\begin{array}{c}\text { Extreme temperature } \\
\text { indices }\end{array}$ & Hurst exponents & $\begin{array}{c}\text { Extreme precipitation } \\
\text { indices }\end{array}$ & Hurst exponents \\
\hline FD & 0.353 & CDD & 0.440 \\
Tnn & 0.428 & CWD & 0.442 \\
Tnx & 0.433 & R10 & 0.338 \\
Tn10 & 0.556 & R20 & 0.362 \\
Tx10 & 0.691 & R50 & 0.412 \\
SU & 0.570 & R95p & 0.446 \\
Txn & 0.440 & R99p & 0.494 \\
Txx & 0.405 & SDII & 0.493 \\
Tn90 & 0.802 & PRCPTOT & 0.320 \\
Tx90 & 0.473 & & \\
\hline
\end{tabular}

\section{Conclusions and discussion}

Under the general context of global warming, this study used daily meteorological data at 39 stations from MDSCC for the period 1968 to 2017. The 19 extreme climate indices recommended by the WMO were selected. Linear regression analysis, M-K test, sliding $\mathrm{T}$ test, wavelet analysis, correlation analysis and R/S analysis were performed for these indices. The interannual spatio-temporal variations, mutation and period features of extreme temperature and precipitation of Sichuan in the past 50 years were analyzed. On this basis, we further discussed the correlation between the extreme climate indices and geographical factors. Finally, some future trends were predicted based on the Hurst exponents. The main conclusions and discussion will cover the five aspects of this research.

(1) As to interannual temporal variations in the past 50 years (Fig. 3), in five extreme cold indices, the linear tendency rates of FD, Tn10 and Tx10 showed a decreasing trend, while those of Tnn and Tnx showed a warming trend. The five extreme warm indices include SU, Txn, Txx, Tn90 and Tx90, where their linear tendency rates indicated either an increasing or a warming trend. That is, most of extreme cold indices of Sichuan showed a decreasing trend, while the extreme warm indices showed a warming trend. Moreover, there was an asymmetry in temporal variation features of the extreme cold 
and warm indices. Generally speaking, warming was predominant in the Sichuan Province. The results observed are in agreement with other research previously carried out in the Southwestern China (Sun, et al., 2012; Qin, et al., 2015; Yuan and Zheng, 2015; Luo, et al., 2016) and Sichuan Province (Sun, et al., 2017). However, the interdecadal variation tendency rates of extreme temperature indices are different. For instance, Sun et al. (2017) found that the inter-decadal variation tendency rates for Txx, Txn, Tnx and Tnn were $0.4{ }^{\circ} \mathrm{C} / 10 \mathrm{a}, 0.3{ }^{\circ} \mathrm{C} / 10 \mathrm{a}, 0.2^{\circ} \mathrm{C} / 10 \mathrm{a}, 0 .{ }^{\circ} \mathrm{C} / 10 \mathrm{a}$, respectively. The discrepancies may be caused by the data with different time periods and number of different meteorological stations used in the two studies.

The interannual variation of the extreme precipitation indices in Sichuan was not significant for the past 50 years (Fig. 4). Among them, R10, R95p, R99p and SDII displayed a mild increasing trend, and all remaining indices of CDD, CWD, R20, R50 and PRCPTOT exhibited decreasing tendencies. Nevertheless, some violent fluctuations occurred, and a regional peak appeared every 5 years. The temporal trends in our work are similar to previous studies in reporting trends of precipitation extremes over the past few decades in the Southwestern China (Sun, et al., 2012; Yuan, et al., 2014; Luo, 2015; Qin, et al., 2015) and Sichuan Province (Sun, et al., 2017; Li, et al., 2019a). For example, in Li's work (2019a), they found the trends in extreme precipitation indices constituted slight changes in the Sichuan Province and extreme precipitation was a fluctuation process from 1961 to 2017. Results showed that the ENSO (El NiñoSouthern Oscillation, ENSO) events have long and strong relations with extreme precipitation. Sun et al. (2017) noted that the overall change trend of precipitation in Sichuan Province was not significant from 1971 to 2012.

(2) As to spatial change trends (Fig. 7), among 5 extreme cold indices, FD, Tn10 and Tx10 showed a decreasing trend in space, while Tnn and Tnx were the opposite. The 5 extreme warm indices showed a warming or increasing trend. The extreme temperature in Sichuan exhibited an increasing trend during the past 50 years. The cold extreme events showed a warming or decreasing trend, while the warm extreme events showed a warming or increasing tendency. The variation trend in the west was more significant than that in the east, that is, the warming amplitude was higher in the PNW and MSW than in ESB. Particularly, the mountain to basin transition regions (Muli and Yuexi Station), as well as high-altitude areas were the most affected by global warming. Li et al. (2012) studied the altitude dependency of trends of daily climate extremes in Southwestern China from 1960 to 2008. Characteristics of regional trends indicated the obvious warming with altitude. There is an enhanced sensitivity of climate extremes to elevation in southwestern China in the context of recent warming, and which are consistent with our results.

There were noticeable spatial and regional differences in the extreme precipitation events in Sichuan during the past 50 years (Fig. 8). Precipitation increased in PNW and MSW, and significantly decreased in ESB. In particular, precipitations registered in the Ya'an, Emeishan, and Leshan Station where the precipitation used to be very abundant, showed a decrease. Among different regions, the precipitation as well as extreme precipitation events in PNW and MSW considerably increased. In detail, the number of heavy rain, rainstorm and very heavy precipitation events in the plateau increased. There was also arise in the number of extreme precipitation events in the mountainous regions. However, the amplitude was not as large as that observed in the plateau. The basin, however, displayed a drying trend with decreased precipitation, and the extreme precipitation was also reduced. Previous studies have reported that the intensity, 
frequency, and duration of extreme precipitation increased in the Sichuan plateau, while the intensity and frequency of extreme precipitation decreased, but the duration of extreme precipitation did not change in the Sichuan basin (Li, et al., 2019a). Sun et al. (2017) determined that the precipitation distribution was low in the western Sichuan and high in the eastern Sichuan, and most of the extreme precipitation indices had no significant change trend. Although the average change trend and spatial distribution of CDD and CWD indicated that the Sichuan as a whole tended to dry, the humidity in some areas of the plateau increased from 1971 to 2014. Our results are roughly consistent with the previous work above.

(3) As shown by the M-K test, sliding $\mathrm{T}$ test and wavelet analysis (Table 3), of 10 extreme temperature indices, except for the mutation year of Tnx in 1995, there were no significant mutation years in the other extreme temperature indices. That is, there were no significant mutation in extreme temperature, but the increase and warming trend of temperature were obvious in the 1980 s and the early $21^{\text {st }}$ century. Except for FD and Tn10 that had no significant wavelet periods, Tnn, SU and Txn showed significant variation with a period of 2-6 years, and for Tnx and Txx were all 2-4 years, and for Tx10, Tn90 and Tx90 were all 3-4 years. Of 9 extreme precipitation indices (Table 4), except for R50, R95p, R99p and PRCPTOT that had mutation years occurred in 1980, 2010, 2004 and 1991, respectively, the other indices had no mutation years. Namely, mutation years corresponding to heavy and very heavy precipitation events mainly appeared in the 1980 and the early $21^{\text {st }}$ century. Except for CDD and CWD that had significant variation with the periods of 2-4 years and 2-5 years, R50, R95p and SDII showed significant variation with a period of 2-7 years, and for R10, R20, P99p and PRCPTOT were all 2-6 years.

The method of M-K trend test is a valuable tool for effectively differentiating natural fluctuations from definite variation trends. It is a nonparametric statistical test to analyze the variation trends of climate and hydrological series over time (Song et al., 2019). But sometimes there are false mutation points in the results of the test. The method of sliding $\mathrm{T}$ test is also helpful in detecting climate mutations by determining if there is a significant difference in the means of two different groups. To ensure the scientificity and accuracy of this research, the M-K and sliding T tests (subseries length 5) were simultaneously used for cross-validation. By using M-K trend test, Luo et al. (2016) conducted mutation test of Tx90, Tx10, Tn90 and Tn10 in Southwestern China from 1970 to 2010 . The results showed that there was an obvious mutation in the number of warm days in 2004, and there was a significant increase in the number of warm days from 2005 to 2010; the number of cold nights had an obvious mutation in 1994 and decreased significantly from 1995 to 2010; the number of cold days had a mutation in 1997, but it was not obvious; the number of warm nights had no mutation. Liu and $\mathrm{Xu}$ (2014) also discussed the mutation years of some extreme temperature indices in Southwestern China. Results indicated there were no mutation years of Tx90 and Tnn from 1951 to 2010; however, increasing temperature trends were noticeable in the early $21^{\text {st }}$ century, which are in agreement with our results. Other discrepancies may be caused by the data with different time periods, extent of different study areas and singularity of mutation method used in the previous studies.

About the abrupt change point of extreme precipitation, Zhang and Ma (2011) indicated there was no mutation in the number of days of annual average extreme precipitation in Sichuan Province from 1961 to 2009. The intensity of extreme precipitation increased before 1990s, and there was a significant mutation point in 1980. 
After 1990s, the trend was decreased and there was a mutation before and after 2002, but it was not significant. Li et al. (2019a) analyzed mutation characteristics of extreme precipitation by using M-K test, and found R20, CWD and SDII were not detected the abrupt change point from 1961 to 2017 in Sichuan Province, moreover, most of the break points were in 1979 and 1991, which are consistent with our work.

Wavelet analysis can accurately provide information on local signal features in both, the time and frequency domains, and can be used for multi-scale detailed signal analysis. Luo et al. (2016) investigated the periodic characteristics of extreme temperature in Southwestern China, the results showed both the number of warm days and the number of warm nights had a short period of 3-4 years and a long period of 14 years, the number of cold days had a short period of 4 years, and two long periods of 7 years and 11 years, and the number of cold nights had a short period of 1-4 years, two long periods of 7 years and 10 years. The results of short period are in accord with our work, but the difference of long-period analysis may be caused by the data with different time periods, extent of different study areas and different specific method of wavelet analysis used in the two studies. In term of periodic characteristics of extreme precipitation, our results are roughly consistent with the previous work of $\mathrm{Li}$ et al. (2019a). As pointed by Li et al. (2019a), the ENSO events have the longest and strongest relations with extreme precipitation in the Sichuan Province.

(4) According to the correlation analysis between extreme temperature indices and geographical factors (Table 5), the results showed that Tnn, Tnx, SU, Txn and Txx were negatively correlated to elevation, and positively to longitude. Tnn, Tnx, Txn and Txx were negatively correlated to latitude. This indicated that the higher the altitude, the lower the longitude and the lower the latitude, the closer to the southwestern mountain area of Sichuan, the greater the change of the given extreme index value. Warmer extreme minimum and extreme maximum temperatures mainly occurred in the western alpine plateau area, and the warming range was larger as compared to that of the eastern basin. FD and Tn10 were positively correlated to elevation and latitude, and negatively to longitude. This indicated that the higher the altitude, the higher the latitude and the lower the longitude, the closer the alpine plateau area in northwest Sichuan, the greater the change of extreme index value, the greater the reduction of extreme cold events in the west, and the smaller the reduction in the eastern basin. The results of correlation analysis between extreme precipitation indices and geographical factors also indicated that the higher the altitude, the lower the longitude and the higher the latitude, the closer the plateau and mountainous area in west Sichuan, the greater the change of extreme index value.

The terrain of Sichuan is higher in the west and lower in the east, and the variation from west to east is mainly plateau-mountain-basin, and its position change is very related to longitude, latitude and altitude. Changes of extreme climate indices are highly related to longitude, latitude and altitude. Previous studies have reported that warming at high elevation regions appeared much more rapid than at low elevations on the basis of ice cores data from the Tibetan Plateau (Tian et al., 2006; Kang et al., 2007). Li et al. (2012) indicated for precipitation extremes, it was obvious that the larger decreasing in summit station than others, and following was flat stations, but the increase mainly in valley stations, which are also consistent with our studies.

(5) As shown by Hurst exponents and interannual variation trends of the 19 extreme climate indices (Table 6), in the future, FD, SU and Tn90 may increase, while Tn10, Tx10 and Txx may decrease, i.e., as a whole, extreme cold events will decrease and 
extreme warm events will increase. Of all extreme precipitation indices, R20, R50 and PRCPTOT may increase, while R10 may decrease. That is, the precipitation and the number of heavy precipitation and rainstorm events will increase, and that both the extreme temperature and extreme precipitation events of the Sichuan Province will increase, but there will be obvious regional differences under different topographic zones in the future. Among them, the results on the overall trend of future change are in agreement with many model projections of extreme climate change. (Liu et al., 2012; Li et al., 2019b; Peng et al., 2019; Zhao et al., 2019).

In this study, some future trends of extreme climate indices are predicted only based on the Hurst exponents. Because climate models are a powerful tool to study climate system and climate change, and its simulation results are an important data base for climate projection and climate change risk assessment. Furthermore, the use of climate models to assess and predict the future climate change features can provide a scientific basis for adjusting human development strategies to adapt to climate change. In the future research, we can use the simulation results of CMIP5 (Coupled Model Intercomparison Project Phase 5, CMIP5) model and high-resolution statistical downscaling data set, combined with RCPs (Representative Concentration Pathways, RCPs) proposed by IPCC, to project the possible future changes of extreme climate events in Southwestern China, even in Sichuan Province. Moreover, the mechanistic understanding of how some climate drivers impact extreme temperature and extreme precipitation in Sichuan Province through forcing large-scale atmospheric circulation changes need to be further investigated, especially, the relationships between ENSO events, SASM (South Asian Summer Monsoon, SASM), EASM (East Asian Summer Monsoon, EASM) and extreme climate indices need to be further discussed, and the analyses of the physical causes of these variability will also become the basis of our future work.

Acknowledgements. This research was funded by the Soft Science Research Project, Science \& Technology Department of Sichuan Province, China (2017ZR0043, 2015GZ0238) and National Natural Science Foundation of China (NSFC) (41971308, 41505122, 41275033).

\section{REFERENCES}

[1] Alexander, L. V., Zhang, X., Peterson, T. C., Caesar, J., Gleason, B., Klein Tank, A. M. G., Haylock, M., Collins, D., Trewin, B., Rahimzadeh, F., Tagipour, A., Rupa Kumar, K., Revadekar, J., Griffiths, G., Vincent, L., Stephenson, D. B., Burn, J., Aguilar, E., Brunet, M., Taylor, M., New, M., Zhai, P., Rusticucci, M., Vazquez-Aguirre, J. L. (2006): Global observed changes in daily climate extremes of temperature and precipitation. - Journal of Geophysical Research Atmospheres 111(D05109). DOI: 10.1029/2005JD006290.

[2] Arnone, E., Cusshi, M., Gesso, S. D., Petitta, M. (2018): A multi-hazard extreme climate index across Europe. - EPiC Series in Engineering 3: 95-102.

[3] Ding, W. R. (2014): Spatial and temporal variability of the extreme daily precipitation in southwest China. - Resources and Environment in the Yangtze Basin 23(7): 1071-1079.

[4] Ding, Z. Y., Ge, Y. X., Abuduwaili, J., Pu, J. (2018): Trends of extreme temperature and precipitation in Ebinur Lake basin in Xinjiang during the period from 1957 to 2012. Journal of University of Chinese Academy of Sciences 35(2): 160-171.

[5] Dookie, N., Chadee, X. T., Clarke, R. M. (2018): Trends in extreme temperature and precipitation indices for the Caribbean small islands: Trinidad and Tobago. - Theoretical and Applied Climatology. https://doi.org/10.1007/s00704-018-2463-z. 
[6] Easterling, D. R., Evans, J. L., Groisman, P. Y., Karl, T. R., Kunkel, K. E., Ambenje, P. (2000): Observed variability and trends in extreme climate events: a brief review. Bulletin of the American Meteorological Society 81(3): 417-425.

[7] Fu, C. B., Wang, Q. (1992): The definition and detection of the abrupt climatic change. Scientia Atmospherica Sinica 16(4): 482-493.

[8] Gao, T., Xie, L. A. (2014): Study on progress of the trends and physical causes of extreme precipitation in China during the last 50 years. - Advances in Earth Science 29(5): 577-589.

[9] Jiang, R. G., Xie, J. C., Zhao, Y., He, H. L., He, G. H. (2017): Spatiotemporal variability of extreme precipitation in Shaanxi province under climate change. - Theor Appl Climatol 130: 831-845.

[10] Kang, S. C., Qin, D. H., Zhang, D. Q. (2007): Recent temperature increase recorded in an ice core in the source region of Yangtze River. - Chinese Science Bulletin 52: 825-831.

[11] Li, J., Zhao, Y. D., Iqbal, J. (2019a): Variation patterns of extreme precipitation and relation to ocean-atmospheric climate in Sichuan province China from 1961 to 2017. Theoretical and Applied Climatology 137: 3009-3026.

[12] Li, J. J., Wang, A. H., Guo, D. L., Wang, D. (2019b): Evaluation of extreme indices over China in the NEX-GDDP simulated by high-resolution statistical downscaling models. Acta Meteorologica Sinica 77(3): 579-593.

[13] Li, Z. X., He, Y. Q., Wilfred, H. T., Wang, X. F., Zhang, W., Cao, W. H., Du, J. K., Xin, H. J., Chang, L. (2012): Altitude dependency of trends of daily climate extremes in southwestern China, 1961-2008. - J. Geogr. Sci. 22(3): 416-430.

[14] Liu, J. L. (2013): Study on Extreme Temperature and Precipitation Events in Sichuan Basin. - Southwest University, Sichuan.

[15] Liu, L., Xu, Z. Z. (2014): Spatiotemporal distribution of the extreme climate indices in the five southwestern provinces of China. - Resources and Environment in the Yangtze Basin 23(2): 294-301.

[16] Liu, M., Shen, Y. J., Qi, Y. Q., Wang, Y. F., Geng, X. X. (2019): Changes in precipitation and drought extremes over the past half century in China. - Atmosphere 10: 203. DOI: $10.3390 /$ atmos 10040203 .

[17] Liu, X., Zhang, W. Y., Jia, D. Y., et al. (2011b): Research of abrupt changes of sandstorm frequency in Hexi Corridor in recent 50 years. - Journal of Desert Research 31(6): 15791584.

[18] Liu, X. R., Cheng, B. Y., Yang, Q., Zhang, T. Y., Wang, R. Y. (2012): Scenario projections of 21st century climate change in Southwest China. - Journal of Southwest University (Natural Science Edition) 34(9): 82-89.

[19] Liu, Z. F., Wang, Y. C., Yao, Z. J., Kang, H. M. (2011a): Trend and periodicity of precipitation, air temperature and runoff in the Taihu Lake Basin. - Journal of Natural Resources 26(9): 1575-1584.

[20] Luo, Y., Fan, G. Z., Zhou, D. W., Hua, W., Li, J. J. (2015): Extreme precipitation trend of Southwest China in recent 41 years. - Journal of the Meteorological Sciences 35(5): 581586.

[21] Luo, Y., Fan, G. Z., Zhou, D. W., Hua, W., Zhang, Y. L. (2016): Trend of extreme temperature in southwest China in the recent 41 years. - Journal of Southwest University (Natural Science Edition) 38(5): 161-167.

[22] Ma, R., Zhang, M. J., Wang, S. J., Wang, J., Yang, S., Chen, Y. (2018): Variation characteristics of snow cover days in winter in arid region of northwest China in last 50 years. - Journal of Natural Resources 33(1): 127-138.

[23] Ma, X. B. (2016): Sichuan Yearbook. - Sichuan Yearbook Society, Chengdu.

[24] Peng, D. D., Zhou, T. J., Zhang, L. X., Zhang, W. X., Chen, X. L. (2019): Observationally constrained projection of the reduced intensification of extreme climate events in Central Asia from $0.5^{\circ} \mathrm{C}$ less global warming. - Climate Dynamics https://doi.org/10.1007/s00382-019-05014-6. 
[25] Qin, N. X., Wang, J. N., Yang, G. S., Liang, H. Y., Zhang, J. B. (2015): Spatial and temporal variations of extreme precipitation and temperature events for southwest China in 1960-2009. - Geoenvironmental Disasters 2: 4. DOI: 10.1186/s40677-015-0014-9.

[26] Sajjad, H., Ghaffar, A. (2018): Observed, simulated and projected extreme climate indices over Pakistan in changing climate. - Theoretical and Applied Climatology 137: 255-281.

[27] Sohrabi, M. M., Ryu, J. H., Abatzoglou, J., Tracy, T. (2013): Climate extreme and its linkage to regional drought over Idaho, USA. - Nat Hazards 65: 653-681.

[28] Soltani, M., Laux, P., Kunstmann, H., Stan, K., Sohrabi, M. M., Molanejad, M., Sabziparvar, A. A., SaadatAbadi, A. R., Ranjbar, F., Rousta, J., Zawar-Reza, P., Khoshakhlagh, F., Soltanzadeh, I., Babu, C. A., Azizi, G. H. (2016): Assessment of climate variations in temperature and precipitation extreme events over Iran. - Theor Appl Climatol 126(3-4): 776-795.

[29] Song, X., Zhang, Z., Chen, Y., Wang, P., Ming, X., Shi, P. J., Tao, F. L. (2013): Spatiotemporal changes of global extreme temperature events (ETEs) since 1981 and the meteorological causes. - Nat Hazards 70(2): 975-994.

[30] Song, X. M., Zou, X. J., Zhang, C. H., Zhang J, Y., Kong, F. Z. (2019): Multiscale spatiotemporal changes of precipitation extremes in Beijing-Tianjin-Hebei region, China during 1958-2017. - Atmosphere 10(8): 462-490.

[31] Stocker, T. F., Qin, D., Platter, G. K., Tignor, M., Allen, S. K., Boschung, J., Nauels, A., Xia, Y., Bex, V., Midgley, P. M. (2013): IPCC: Summary for Policymakers. - In: Climate Change 2013: The Physical Science Basis. Contribution of Working Group I to the Fifth Assessment Report of the Intergovernmental Panel on Climate Change. Cambridge University Press, Cambridge.

[32] Sun, C., Cheng, Z. G., Mao, X. L., Mei, S. D., Yang, X., Y. (2017): Extreme climatic change trend and features in Sichuan for the latest 44 years. - Journal of Lanzhou University: Natural Sciences 53(1): 119-126.

[33] Sun, J. Q., Chen, H. P., Zhu, Y. L. (2012): Extreme climate in China: facts, simulation and projection. - Meteorologische Zeitschrift 21(3): 279-304.

[34] Tariku, T. B., Gan, T. Y. (2018): Regional climate change impact on extreme precipitation and temperature of the Nile River basin. - Climate Dynamics 51: 34873506.

[35] Tian, L. D., Yao, T. D., Li, Z., Kenneth, M. C., Wu, G. G., Xu, B. Q., Li, Y. F., Lu, A. X., Shen, Y., P. (2006): Recent rapid warming trend revealed from the isotopic record in Muztagata ice core, eastern Pamirs. - Journal of Geophysical Research 111: D13103. DOI: $10.1029 / 2005 J D 006249$.

[36] Vogel, M. M., Zscheischler, J., Seneviratne, S. I. (2018): Varying soil moistureatmosphere feedbacks explain divergent temperature extremes and precipitation projections in Central Europe. - Earth Syst. Dyn. 9(3): 1107-1125.

[37] Wang, C. X., Wei, Y. Y., Ye, X. B., Wu, X., Yan., Liu, Y. Y. (2017): Drought index estimation and drought characteristics in Sichuan province. - Journal of Agricultural Catastrophology 7(1): 36-48.

[38] Wei, F. Y. (2007): Modern Climate Statistical Diagnosis and Prediction Technology. Second Ed. - China Meteorological Press, Beijing.

[39] Xu, Y. Q., Li, S. C., Cai, Y. L. (2004): Study on precipitation variation in Hebei Plain based on Wavelet Analysis. - Science in China Ser. D Earth Sciences 34(12): 1176-1183.

[40] Yang, P., Liu, W. D., Wang, Q. G., Xiong, K. G., Hou, W. (2010): The climatic change trend and seasonal characteristics of daily temperature extremes in China for the latest 40 years. - Journal of Applied Meteorological Science 21(1): 29-36.

[41] Yin, H., Sun, Y. (2019): Characteristics of extreme temperature and precipitation in China in 2017 based on ETCCDI indices. - Climate Change Research 15(4): 363-373. 
[42] Yuan, W. D., Zheng, J. K. (2015): Spatial and temporal variations of extreme temperature events in southwest China during 1962-2012. - Resources and Environment in the Yangtze Basin 24(7): 1246-1254.

[43] Yuan, W. D., Zheng, J. K., Dong, K. (2014): Spatial and temporal variations in extreme precipitation events in southwest China during 1962-2012. - Resources Science 36(4): 0766-0772.

[44] Zhan, Z. Y., Wen, K. G. (2006): China Meteorological Disaster Ceremony (Volume Sichuan). - China Meteorological Press, Beijing.

[45] Zhang, S. Q., Ma, Z. F. (2011): Change tendency and cyclicity analysis of extreme precipitation over Sichuan province during 1961-2009. - Journal of Natural Resources 26(11): 1918-1929.

[46] Zhao, A. Z., Liu, X. F., Zhu, X. F., Pan, Y. Z., Zhao, Y., L., Wang, D. L. (2016): Trend variations and spatial difference of extreme air temperature events in the Loess Plateau from 1965 to 2013. - Geographical Research 35(4): 639-652.

[47] Zhao, J., Wang, N. A., Yang, S. H. (2000): R/S analysis of urbanization effect on climate in Lanzhou. - Journal of Lanzhou University (Natural Sciences) 36(6): 122-128.

[48] Zhao, Y. Q., Xiao, D. P., Bai, H. Z. (2019): Projection and application for future climate in China by CMIP5 climate model. - Meteorological Science and Technology. 47(4): 608-621.

[49] Zhou, C. Y., Cen, S. X., Li, Y. Q., Peng, G. Z., Yang, S. Q., Peng, J. (2011): Precipitation variation and its impacts in Sichuan in the last 50 years. - Acta Geographica Sinica 66(5): 619-630. 